$\mathrm{BER} / \mathrm{TP}--11-83$

DESA 001837

EINAL REPORT

GEOSCIENCE-RELATED RESEARCH NEEDS

FOR GEOTHERMAL ENERGY TECHNOLOGY

SEPTEMBER 30, 1983

Prepared For:

Office of Program Analysis

U.S. Department of Energy

Project officer:

Charles Mandelbaum

Prepared By:

Christopher H. Crane

Joseph J. Markiewicz, Jr.

Engineering and Economics Research, Inc.

1951 Kidwel1 Drive, Suite 201

Vienna, VA 22180

Contract No. DE-AC01-82ER30041

\title{
NOTICE
}

PORTIONS OF THIS REPOAT ARE ILLEGIBLE.

It has been repruduced from the best available copy to permit the broatest possible availabitity. 
This report was preparəd as an account of work sponsored by an agency of the United States Government. Neither the United States Government nor any agency thereof, nor any of their employees or contractors, makes any warranty, express or implied, or assumes any legal liability or responsibility for the accuracy, completeness, or usefulness of any information, apparatus, product, or process disclosed, or represents that its use would not infringe privately owned rights. Reference hereln to any specific commercial product, process, or service by trade name, trademark, manufacturer, or otherwise, does not necessarily constitute or imply its endorsement, recommendation, or favoring by the United States Government or any agency thereof. The views and opinions of authors expressed herein do not necessarily state or reflect those of the United States Government or any agency thereof. 
$\begin{array}{ll}1.0 & \text { INTRODUCTION } \\ & 12\end{array}$

1.1 Role of the Office of: Exergy Research 12

$\begin{array}{ll}1.2 & \text { Purpose of the Study } \\ 1.3 & 12\end{array}$

1.3 General Approach 13

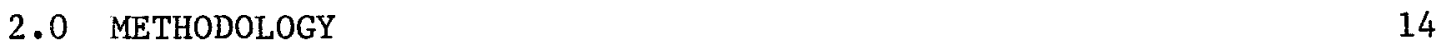

2.1 Panel of Experts 14

2.2 R\&D Project Information 16

2.3 Pane1 Meeting 17

2.4 Preparation of Technical Report 18

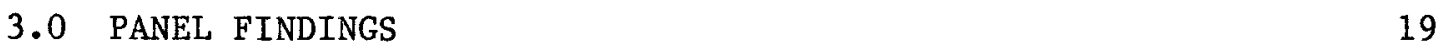

3.1 Generic Research Needs and Priorities 20

3.2 Specific Research Needs and Priorities 23

3.2.1 Reservoir Engineerźng 24

3.2.1.1 Deduction of Physical Properties and Processes 27

3.2.1.2 High-Temperature Downhole Equipment 28

3.2.1.3 Tracer Studies 28

3.2.1.4 Transient We1.1 Testing 30

3.2.1.5 Numerical Simulation 32

3.2.1.6 Production and Injection Strategies 33

3.2.1.7 Laboratory Studies $\quad 34$

3.2.2 Resource Exploration and Reservoir Definition 35

3.2.2.1 Joint Interpretation of Data 37

3.2.2.2 Conceptual Model for Extensional Geologic 38

3.2.2.3 Conceptual Model for Subductive Geologic 39

3.2.2.4 Development and Testing of New/Improved 40

3.2.2.5 Conceptual Model for Bimodal Rhyolite/Basalt 40 Geologic Environment

3.2.2.6 Conceptual Model for "Hot Spots" Geologic 43

3.2.2.7 Conceptual Model for Intracratonic Basins 43

3.2.2.8 Conceptual Models for Other Geologic 44 Environments 
3.2.3 Well Drilling, Completion, and Stimulation 45

3.2.3.1 Drilling Equipment and Techniques 47

3.2.3.2 Stimulation Techniques 49

3.2.3.3 High-Temperature, High-Pressure Borehole 51 Instrumentation

3.2.3.4 Deliverability Testing - - Single We11 53

3.2.3.5 Completion Technology 54

3.2.3.6 Scale Control 55

3.2.3.7 Borehole Heat Transmission and Fluid 56

3.2.4 Environmental Moaitoring and Control 57

3.2.4.1 Pre-Injection Brine Treatment Techniques 59

3.2.4.2 Monitor Industry Activities Related to 60

Other Environmenta1 Issues

3.3 Potential Research Performers 61

3.3.1 Reservoir Engineering 62

3.3.2 Resource Exploration and Reservoir Definition 62

3.3.3 Well Drilling, Completion, and Stimulation 62

3.3.4 Environmental Monitoring and Control 63

$\begin{array}{lll}4.0 & \text { SUMMARY OF RESEARCH NEEDS } & 64\end{array}$

APPENDIX A - Information Suurces for R\&D Projects 68

APPENDIX B - The Role of Geosciences in the Assessment, 70 Exploration, and. Development of Geothermal Energy Resources 


\section{LIIT OF EXHIBITS}

Exhibit

$\underline{\text { Page }}$

ES-1 Federal Research Needs and Priorities

2

1 Panel of Experts

15

2 Federal Research Needs, Priorities, and Levels of

25 Activity in Reservoir Engineering

3 Federal Research Needs, Priorities, and Levels of Activity in Resource Exploration and Reservoir Definition

4 Geoscience Techniques in Need of Research, Development, or Testing

5 Federal Research Needs, Priorities, and Levels of Activity in Well Drilling, Completion, and Stimulation

6 Federal Research Needs, Priorities, and Levels of Activity in Environmental Monitoring and Control

7 Federal Research Needs and Priorities 66

B-1 Geothermal Resource Classification $\quad 74$

B-2 Generic High-Temperature Elydrotherma1 Exploration Strategy 77

B-3 Development of a Geotherma1 Resource Model 78 


\section{ACXNOWLEDGEMENTS}

The authors and the DOE Project officer wish to express their gratitude to the Pane1-of-Experts members who devoted their time and expertise to this project:

- Dr. B. Doe (U.S. Geological Survey)

- Dr. R. Fournier (U.S. Geologica1 Survey)

- Mr. B. Greider (Geothermal Resources International, Inc.)

- Dr. B. Hanshaw (U.S. Geological Survey)

- Dr. V. Murthy (University of Minnesota)

- Dr. H. Ramey (Stanford University)

- Mr. V. Roberts (Electric Power Research Institute).

The authors would like to express special appreciation to Dr. Mike Wright of the University of Utah Research Institute who, as a member of the contractor's team, provided invaluable technical assistance in the conduct of the Panel meeting and the preparation of this report. Dr. Roy Mink of Morrison-Knudsen Co., Inc. is also acknowledged for his input to the project. 
The Office of Energy flesearch (OER) within the U.S. Department of Energy (DOE) is responsible for, among other duties, monitoring DOE R\&D programs and advisiag the Secretary with respect to possible program improvements. In keeplng with this function, OER sponsored a project to identify and prioritize geoscience-related research needs that would be of significant benefit in the assessment, exploration, and development of U.S. geothermal energy resources. This project relied on the expertise of a specially-assembled Panel-of-Experts consisting of representatives of federal government, industry, and academia. (The Panel members are identified in Exhibit 1 on page 15). The Panel reviewed supporting documentation relating to recent research in this area, met for two days in Washington, D.C. to discuss and recommend research needs, and reviewed and commented upon two draft reports of the Panel's findings.

Exhibit ES-1 sumnarizes the federal research needs as identified by the Panel. The research needs are organized into specific research needs for four technology areas and a group of generic research needs which relate to all of the technology areas. The technology areas correspond to the major geoscience-related activities engaged in by a potential geothermal resource developer. Arranged in order of overall need for research, these technology areas are:

- Reservoir Engineering

- Resource Exploration and Reservoir Definition

- We11 Drilling, Completion, and Stimulation

- Environmental Monitoring and Control. 
EXHIBIT ES-1

FEDERAL RESEARCH NEEDS AND PRIORITIES

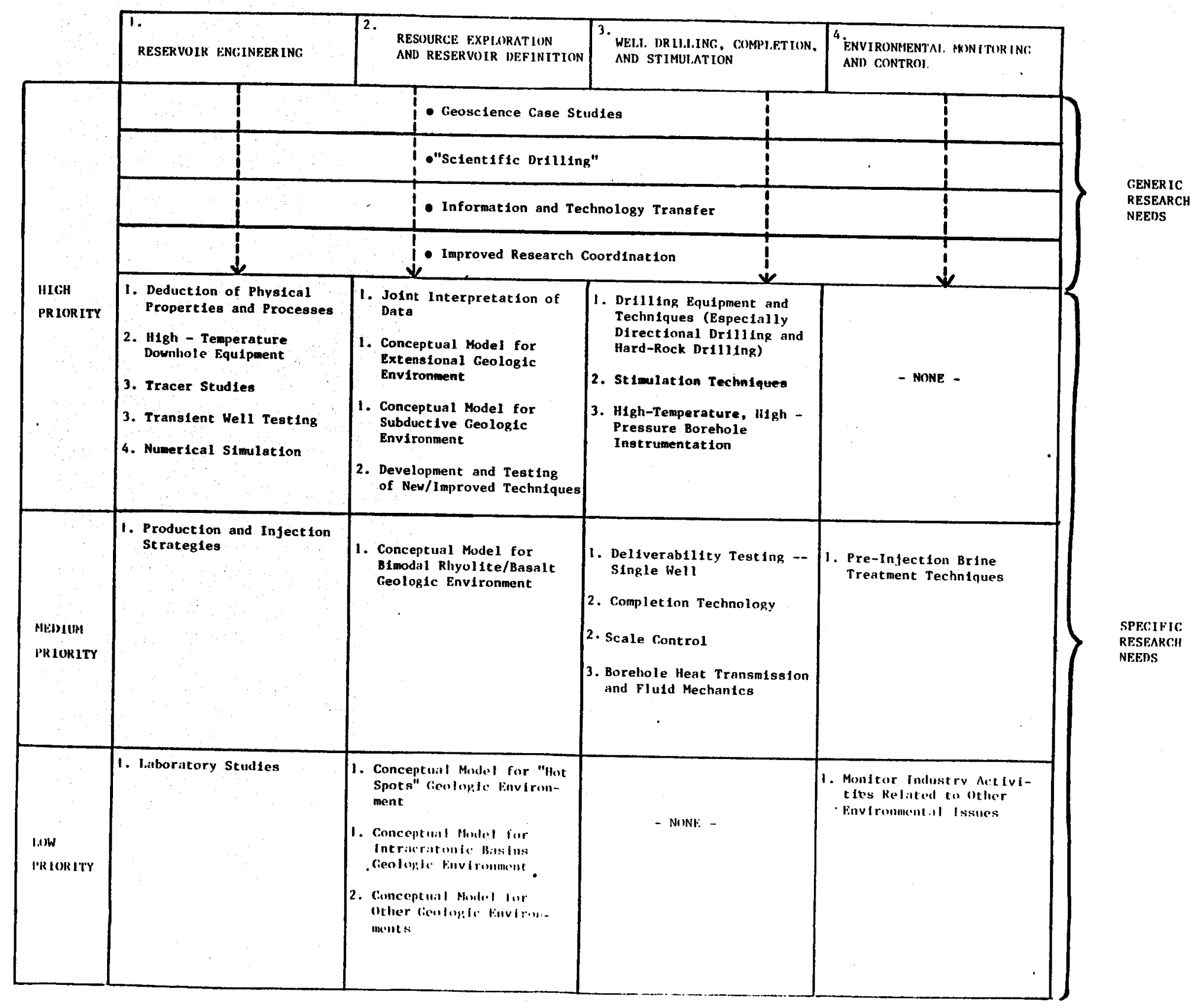


(In Exhibit ES-1, "Reservoir Engineering" is labelled " 1 " and is the highest-priority area, while "Environmental Monitoring and Control" is labelled "4" and is the lowest-priority area.) The research needs for each technology area ane divided into high-, medium-, and lowpriority groups. In addition, the research needs within each priority-group are ranked on a $1,2,3 \ldots$ basis, indicating higher-to-lower importance. The Panel did not address the issue of prioritizing the research needs across the four technology areas.

Together, the research needs identified for the four technology areas reflect the fact that significant advances are required in every major facet of resource exploration, production, and long-term management. The petroleum and minerals industries have at their disposal a comprehensive geoscience-related technology base that has been developed and refined over many decades. Geothermal systems represent a subsurface environment which is fundamentally different in a number of ways from that encountered in these other industries and about which relatively little is known. From the viewpoint of the potential geothermal resource developer, this situation is exacerbated by the overall inadequacy of petroleum industry based equipment and techniques when applied to geothermal data gathering/interpretation and field development. Furthermore, not enough is known about the production characteristics and longevity of geothermal resources nor about the pace and scale of geothermal energy development to warrant committing significant $R \& D$ capital. The perceived risks resulting from this lack of fundamental geoscience information do not favor geothermal energy since it must compete in the capital marketplace against better-established or what are believed to be more promising energy ventures. 
Four high-priority generic research-related needs were identified which could make significant contributions to all four technology areas. Brief descriptions of these "across-the-board" issues are given below; these are presented in no intended order of priority.

- Geoscience case studies. Much industry-developed data is proprietary and there is insufficient geoscience information in the public domain from which to construct a fundamental understanding of geothermal systems. Selected geoscienceoriented case studies, similar to that sponsored by DOE at Cerro Prieto over the last few years, would be extremely valuable in advancing the understanding of geothermal systems.

- "Scientific drilling". The federal government has generally funded the drilling of geothermal wells only for certain site-specific resource assessment or development purposes. It is strongly recommended that the government support the drilling of wells at scientifically-selected sites for the purpose of collecting reliable basic data. The unavailability of those data has so far been limiting the understanding of the interaction of a heat source and its hydrothermal system. The drilling of such research holes could be cost-shared with industry and/or might form a component of a geoscience case study as mentioned above.

- Information and technology transfer. The continuing transfer of timely information and technology developed under federal sponsorship to the potential user community is a vital activity requiring a sustained government commitment. Technical reports and conferences/workshops are particularly effective and efficient: mechanisms for this.

- Improved research coordination. There are several very important and highly-relevant research topics that are being addressed by various federal programs outside of geothermal energy interests. These topics include basic geochemical research, basic rock properties research, and hydrological/reservoir engineering modeling. Such research is being funded in support of nuclear waste isolation, toxic waste isolation, petroleum-related, and minerals resource related programs. Improved coordination of the research in these different areas could help increase the impact of federal expenditures and provide valuable data which could be used in the geothermal energy area. Improved research coordination includes both program-level and researcher-level elements.

The specific research neads are highlighted below for each of 
the four technology areas.

Reservoir Engineering

Geothermal reservoir engineering comprises those data and techniques needed, once a reservoir has been located, to determine reservoir production characteristics, predict those characteristics into the future, estimate reservir lifetime, and plan and optimize production and injection strategles. Reservoir engineering is an ongoing activity during the productive life of the reservoir, with new production and injection experience being continually used to confirm or modify reservoir management procedures. However, the resource developer must have proven techniques for obtaining and interpreting subsurface data. In addition, site-specific reservoir engineering can benefit tremendously from a fundamental understanding of the origin, nature, and behavior of different types of geothermal systems. Neither adequate techniques nor a working knowledge (models) of geothermal systems are available yet.

The most important high-priority research need concerns the deduction of physical properties and processes, i.e., where the reservoir fluids come from, how they are heated, what effects production and injection have, the subsurface configuration of porosity and permeability, and other considerations. In particular, the complex mechanism of fluid production needs to be fully understood and how physical and chemical data can be most effectively used to develop this understanding must be determined.

There is a high-priority need to improve/develop downhole instru- 
mentation for the high-temperature geothermal environment. Current logging and fluid sampling technologies become unreliable above about $200^{\circ} \mathrm{C}$ and these capabilitie:s need to be extended to at least $300^{\circ} \mathrm{C}$. Two additional high-priority reservoir engineering field techniques of special interest which zeed significant improvements are tracer studies and transient well testing.

Numerical simulation can be an extremely useful tool, but substantial high-priority research is needed to develop valid 3-dimensional, multi-phase, non-isothermal simulators for fractured media. Equations-of-state are essential input for simulators, but only the pure water-steam system is well known at present. Equations-of-state are needed for chemically-complex geothermal fluids.

The only medium-priority item concerns developing data and procedures for optimizing procuction and injection strategies. This includes defining well location/spacing criteria, minimizing the adverse effects and maximizing the benefits of injection, and planning for changes in fluid characteristics during transport to and within the energy conversion facility (especially in terms of corrosion and precipitation/scaling).

The only low-priority research need concerns laboratory investigations to collect basic data on reservoir rocks and fluids, develop scale mode1s, and compare and evaluate data from different sources.

\section{Resource Exploration and Reservoir Definition}

These activities are aimed at locating geothermal resources and defining such resources when found. The fundamental characteristics of geothermal systems are significantly different from petroleum 
resources and, therefore, much of the exploration and reservoir definition technology (including conceptual modeling of resources) transferred from the petroleum industry is inappropriate. These characteristics include the deep hard-rock environment, the fractured nature of formations, the high temperatures and pressures, the chemically-complex natural fluids, and the uncertain origins and recharge controls of reservoir fluids. In addition, the absence of long-term field experience comparable to that for petroleum and minerals resources limits the availability of empirical geothermal data. The research needs in this area center around developing conceptual geologic models fior the different geothermal environments, developing new/improved exploration and definition tools, and integrating existing and new data for the purpose of joint interpretation.

The joint interpretation of data is a high-priority need. This includes collecting new data, integrating these with existing data, and developing new techriques for joint interpretation such as are being worked on in the petroleum industry. To enable the collection of reliable data, new or improved techniques are needed. Among the high-priority surface and subsurface techniques that need development or major improvement are:

- Geological techniques - structural studies; stratigraphic studies; dating; mapping.

- Geochemical techniques - geothermometry; mineralogy/hydrothermal alteration; major, minor, and trace element zoning; gases in soils and waters; isotopic studies of fluids and rocks; water/rock interaction.

- Geophysical techniques - magnetotellurics; audiomagnetotellurics; electromagnetics; self-potential; seismic; heat flow; well logging; data gathering (field surveys). 
The remainder of the ressearch needs involve developing conceptual models for different gecthermal environments. These efforts have been prioritized according $=0$ the relative occurrence and importance of these types of environment, with the extensional geologic environment and the subductive geologic environment assigned high priority.

Well Drilling, Completion, and Stimulation

It is extremely important that well sites are carefully selected and that drilling and completion technology appropriate for geothermal duty is employed. Cost-effective and reliable stimulation techniques will also be instrumental in extending the life of both production and injection wells.

Drilling accounts for approximately half of total geothermal resource development costs. There is a high-priority need for upgraded drilling equipment and techniques (especially directional drilling above $200^{\circ} \mathrm{C}$ and hard-rock drilling above $400^{\circ} \mathrm{C}$ ) to bring down the very high cost of drilling geothermal wells with petroleum technology. Although geothermal wells are being drilled using technology borrowed from the petroleum industry, the attendant risks and costs are too high to support vigorous resource exploration and development by the private sector. The primary features of geothermal drilling which limit the application of petroleum technology are: depth of many high-temperature resources (5,000 - 12,000 feet); hard rock formations; large diameter (6-10 inch) completed holes required to accommodate the large flow rates (up to and sometimes exceeding $1,000,000$ pounds/hour); high temperatures (up to $350^{\circ} \mathrm{C}$ ), which exceed those generally encountered in petroleum reservoirs; and hot corro- 
sive reservoir fluids. Drilling into magma bodies, which can exceed $1000^{\circ} \mathrm{C}$, presents a major challenge to drilling and completion technology. Special R\&D efforts are needed in the areas of: drill bits, packers, advanced drilling techniques, drilling fluids, tubular goods (drill pipe and casing), and directional control (downhole drilling motors and drilling monitoring) when air is substituted for drilling mud.

The stimulation of geothermal wells to improve their natural productivity or to recover lost productivity is currently very expensive and relatively unreliable. Substantial high-priority research into hydrofracturing is needed, especially for control of fracture direction and dip, detection and mapping of fractures formed, and proppants. Chemical stimulation and, to a lesser extent, explosive stimulation techniques also need investigation and improvement as indicated.

Another high-priority aspect of geothermal drilling and completion is the need for improved high-temperature, high-pressure borehole instrumentation. In particular, geophysical well logging equipment for high-temperature service and improved $10 \mathrm{~g}$ interpretation methods are critical in order to accurately locate and test production zones within a well. This will help in completing the well to obtain optimum production. The ability to obtain uncontaminated samples of native reservoir fluid would also yield valuable data for this purpose as well as for reservoir exploration, definition, and engineering purposes. However, no reliable downhole sampler for operation above about $200^{\circ} \mathrm{C}$ is available at the present time.

A group of four medium-priority topics completes the list of 
research needs in this technology area. These are highlighted below.

- Deliverability testing -- single well. This includes both production and injection well testing. Improved techniques are needed for measuring fluid flow parameters during and just after drilling and for performing in situ geochemical characterization.

- Completion technology. The major completion research needs are for improved casing materials and cements, improved perforation equipment (especially above $200^{\circ} \mathrm{C}$ ), and improved methods of identifying fluid production and injection zones (as discussed above). For production wells, it may be necessary to set a downhole pump within the well to obtain adequate fluid production and/or to prevent flashing. Commercially-available downhole pumps have very short service lives in geothermal applications, and "geothermally hardened" pumps are needed.

- Scale control. Scaling can be a problem downhole, in surface fluid distribution pipelines, and in the energy conversion equipment. A predictive understanding of precipitation and scaling phenomena needs to be gained through modeling and approaches to scale control need to be developed and tested. Scale control techniques include chemical inhibition, control of flashing, and reworking (cleanout of scale from a well).

- Borehole heat transmission and fluid mechanics. A precise understanding of the flow of fluids and heat within a wellbore is essential for several activities, including: design of casings, cements, and casing installation procedures; prediction of fluid enthalpy downhole and at the surface; and determination of point of flashing within the wellbore. Although nearly every geothermal developer has a "borehole simulator" to solve such heat transmission and fluid mechanics problens, none is very satisfactory. Special efforts are needed to improve borehole simulators through simulation of multi-phase flow and determination of the thermodynamic and chemical properties of geothermal fluids.

\section{Environmental Monitoring and Control}

The withdrawal of geothermal fluids (or heat mining in the cases of hot dry rock and magma resources) and the use of these fluids in an energy conversion facility entail a number of actual and potential environmental effects. The development of geothermal resources involves potential generic types of environmental problems, the 
occurrence and severity of which are very site-specific issues. Nearly all of the envirommental effects are related to the act of withdrawing and injecting geothermal fluids and/or to the chemical nature of these fluids. Potential environmental problems include air emissions, water pollution (surface and ground waters), solid wastes, subsidence, and induced seismicity. Environmental problems have not generally been an obstacle to geothermal energy development, although site-specific environmental issues will be a factor in some cases.

The Panel did not feel as qualified in the area of environmental effects as in the other three technology areas, although panel members are experienced in environmental impact and assessment studies and in developing a field in an environmentally-acceptable manner. No high-priority envilronmental research needs were identified. Medium-priority research was limited to the need to develop pre-injection brine treatment to prevent groundwater pollution (especially from boron and arsenic, natural constituents of most geothermal fluids). Low-priority was assigned to the need for federal monitoring of industry activities related to other environmental issues. 


\subsection{INTRODUCTION}

\subsection{Role of the Office of Energy Research}

The Office of Energy Research (OER) was established as a component of the Department of Energy (DOE) by Section 109 of Public Law 95-91 (Department of Energy Organization Act). The statutory functions stated in this act that define the role of OER and of its Director include, among other responsibilities, the following items:

- Monitoring the Department's energy research and development programs in order to advise the secretary with respect to any undesirable duplication or gaps in such programs; and

- Carrying out such additional duties assigned to the office by the Secretary relating to basic and applied research activities including, but not limited to, supervision or support of research activities carried out by any of the Assistant Secretaries designated by Section 202 of this Act, as the Secretary considers advantageous.

The Director of the Jffice of Energy Research functions, in essence, as a science and technology advisor to the Office of the Secretary, with additional responsibilities consistent with the intent of the statute. Further, the Director of OER is the principal advisor to the Secretary on matters relating to physical research programs of the Department, utilization of multi-purpose laboratories, and cross-discipline research and development projects. The Director is assigned management responsibilities for major programs in Basic Energy Sciences, High Energy and Nuclear Physics, Magnetic Fusion Energy, and Health and Environmenta1 Research.

\subsection{Purpose of the Study}

In accordance with the OER functions described above, the purpose of this study is to review recently completed and on-going 
geosciences-related research for geothermal energy development to:

- Identify research needs

- Establish the relative priorities of the research needs

- Identify activities underway that are deemed to be of low priority

- Identify potential performers of the research

- Estimate costs necessary to undertake the research.

\subsection{General Approach}

The identification of çeoscience-related research for geothermal energy development was accomplished primarily through the expertise of a panel formed specifically for this purpose. The general approach involved:

- Forming a panel with recognized technical expertise in geoscience-oriented research and/or geothermal energy exploration/development;

- Collecting and documenting information on recently-completed and on-going geosciences research sponsored or conducted by the federal goverment and other parties;

- Identifying geoscience-related research that would provide significant benefits for the assessment and development of geothermal (hydrothermal, geopressured, hot dry rock, and magma) energy resources;

- Determining the relative priorities of identified research needs in view of the appropriate $R \& D$ role for the federal government; and

- Identifying potential performers and estimating costs of the recommended research. 


\subsection{METHODOLOGY}

The project was conducted in five phases, as described below:

(1) Form the Panel of Experts and apprise the Panel members of their responsibilities.

(2) Collect, organize, document, and supply Panel members with recent information on geoscience-related research projects sponsored by the federal government and by other parties where readily available and obtain any Panel member comments.

(3) Convene a Panel meeting for the purposes outlined in Section 1.2, at which preliminary information obtained from the Panel members in step (2) and other specially-prepared materials are to be used.

(4) Prepare a draft report describing the project and documenting the Panel's findings for submission to the Pane1 members, DOE/OER, and DOE/Geothermal and Hydropower Technologies Division for review and comment.

(5) Prepare the final report incorporating Panel, DOE/OER, and DOE/GHTD input.

\section{$2.1 \quad$ Pane1 of Experts}

Seven individuals recognized as having substantial relevant expertise in geosciences/geothermal research were selected and agreed to serve on a Panel of Experts. The Panel members and pertinent personal data are identified In Exhibit 1 . The Panel was responsible for:

- Determining technical discussion areas relating geosciences to geothermal energy development;

- Identifying technical research needs in these areas;

- Prioritizing the research needs on the basis of both relative impact on geothermal energy exploration and development and the appropriateness of federal involvement;

- Estimating the level and/or scope of effort required to address the identified federally-supported research needs; and

- Identifying potential performers for conducting the identified research. 


\section{EXHIBIT 1}

PANEL OF EXPERTS

\begin{tabular}{|c|c|c|c|}
\hline NAME & EDUCATIONAL BACKGROUND & $\begin{array}{c}\text { AREA OF } \\
\text { EXPERTISE }\end{array}$ & POSITION/AFFILIATION \\
\hline Bruce Doe & $\begin{array}{l}\text { B.s., Geology/Engineering, Univ. of Minn } \\
\text { M.s., Geology, Missouri Schoul of Mines } \\
\text { Ph.D., Geology, Callfornla Tech. }\end{array}$ & Geology & $\begin{array}{l}\text { Research Geologist, U.S. Geological Survey } \\
\text { President, Geochemical Society }\end{array}$ \\
\hline Robert Fournter & $\begin{array}{l}\text { A.B., Geology, Harvard University } \\
\text { Ph.D., Geology, University of California }\end{array}$ & $\begin{array}{l}\text { Geology/Geo- } \\
\text { chemistry/ } \\
\text { Volcanology }\end{array}$ & $\begin{array}{l}\text { Geologist/Chief, Hater-Rock Interaction } \\
\text { Projects, U.s, Geological Survey }\end{array}$ \\
\hline Bob Grieder & $\begin{array}{l}\text { Professional Geological Engineering } \\
\text { Degree, Colorado School of Mines }\end{array}$ & $\begin{array}{l}\text { Geology/ } \\
\text { Eng1neering }\end{array}$ & $\begin{array}{l}\text { President, Geothermal Resources International, } \\
\text { Inc. } \\
\text { Director, Geothermal Resources Council }\end{array}$ \\
\hline Bruce B. Hanshaw & $\begin{array}{l}\text { B.s., Geology, MIT } \\
\text { M.S., Geology, University of Colorado } \\
\text { Ph.D., Geochemtstry, Harvard University }\end{array}$ & $\begin{array}{l}\text { Geology/Geo- } \\
\text { chemistry/ } \\
\text { Hydrology }\end{array}$ & $\begin{array}{l}\text { Act Ing Assistant Director For Research, U.S. } \\
\text { Geological Survey }\end{array}$ \\
\hline Varanasi $R$. Murthy & $\begin{array}{l}\text { B.S., Geology, India } \\
\text { M.S., Geology, Yale Universtty } \\
\text { Ph.D., Geology, Yale University. }\end{array}$ & $\begin{array}{l}\text { Geology/ } \\
\text { Geochemistry }\end{array}$ & $\begin{array}{l}\text { Head of the School of Earth Sciences, University } \\
\text { of Minnesota } \\
\text { Chairman, U.S. National Committee for Geo- } \\
\text { chemistry } \\
\text { Member of the Nat Ional Academy of Science's } \\
\text { Geological Sciences Board }\end{array}$ \\
\hline Henry Ramey & $\begin{array}{l}\text { B.s., Chemical Engineer Ing, Purdue } \\
\text { Ph.D., Chemical Engineering, Purdue }\end{array}$ & $\begin{array}{l}\text { Reservoir } \\
\text { Engineering }\end{array}$ & $\begin{array}{l}\text { Chairman, Petroleum Engineering Department, } \\
\text { Stanford University }\end{array}$ \\
\hline Vasel w. Robert.s & $\begin{array}{l}\text { B.s., Mechanical Engineering, University of } \\
\text { New Mexico }\end{array}$ & $\begin{array}{l}\text { Geochemistry/ } \\
\text { Reservoir } \\
\text { Engineering }\end{array}$ & $\begin{array}{l}\text { Program Manager, Geothermal Power Systems, } \\
\text { Electric Power Research Inst itute }\end{array}$ \\
\hline
\end{tabular}


Panel members were sent an introductory package which outlined the purpose of the study, Panel member responsibilities, and $R \& D$ activities (Nov. 1, 1982). Contact was maintained as needed throughout the project with the Panel nembers.

\subsection{R\&D Project Information}

Information on recently-completed and on-going geoscience R\&D projects related to, or of interest to, geothermal energy assessment, exploration, or development was collected and provided to the Panel members prior to the Panel neeting. This information was intended as supporting documentation fcr the Panel's discussions. (The major information sources used for this purpose are identified in Appendix A.)

Information on 338 projects was collected and formatted into project-description sheets. An R\&D classification system was developed and used to organize the projects according to R\&D type (e.g., basic research) and $R \& D$ area (e.g., isotopic geochemistry). From this information, a summary $R \& D$ classification matrix was prepared which allows the reader to quickly gain an impression of the $R \& D$ areas being addressed and the types of R\&D activity involved. This information was submitted to the Panel members in three packages between Dec. 9, 1982 and March 22, 1983. Due to the bulk of the project-related information compiled and to its secondary interest in this document, it is being submitted under separate cover as a supplement to this report. 


\subsection{Pane1 Meeting}

The Panel meeting was held on June 1-2, 1983 at the Dulles International Airport Marriott Hotel near Washington, D.C. The Panel members present were Dr. R. Fournier (USGS), Dr. B. Doe (USGS), Mr. B. Greieder (Geothermal Rasources International, Inc.), and, for about half of the first day, Dr. H. Ramey (Stanford University). The meeting was conducted on an informal basis, with the Panel encouraged to offer ideas on how research needs should be identified, organized, and prioritized as well as performing these tasks.

As described in Sections 1.2 and 2.1 , the Panel was responsible for identifying and prioritizing research needs. A set of criteria had been developed under the contract and proposed for the Panel's use for this purpose. The criteria included two screening criteria (ultimate use of the researih; private sector role) and four evaluation criteria (timeliness of the research; economic competitiveness; capability and willingness of the research communty; criticality). The screening criteria were to be used to ensure that recommended research items would be only those of significant benefit and, at the same time, those that would not be undertaken by the private sector. The evaluation criteria were then to be applied to the screened research needs to determine their relative priorities. Although the Panel members were aware of these criteria prior to and during the meeting, DOE and the Panel decided not to explicitly use these criteria in the prioritization process. The Panel was, however, requested to consider the types of issues represented by these criteria in its deliberations. 


\subsection{Preparation of Technical Report}

The preparation of the project report involved three stages:

(1) Preparation of a brief preliminary account of the Panel's findings during its two-day meeting for submission to the Panel members, DOE/OER, and DOE's Geothermal and Hydropower Technologies Division. (submitted June 21).

(2) Preparation of an expanded draft technical report incorporating review comments received on the preliminary document (submitted Aurgust 26).

(3) Preparation of final report incorporating review comments received on the draft.

Comments on the preliminary and draft reports were received from all

Panel members and the DOE/OER Project Officer. This final report reflects these comments as appropriate. 
3.0 PANEL FINDINGS

The information and reconmendations presented in this section have been distilled from the discussion and conclusions of the Panel-of-Experts during the Panel meeting and from comments received on subsequent individual review of the preliminary and draft reports of the Panel's findings. R\&D needs were identified within the context of the four major geoscience-oriented technology areas involved in geothermal energy development. In order of importance, (in terms of needed research), these technology areas are:

- Reservoir Engineering

- Resource Exploration and Reservoir Definition

- Well Drilling, Comp1etion, and Stimulation

- Environmental Monitoring and Control.

Both generic and specific research needs were identified. The generic needs are "across-the-board" issues which would have wideranging benefits in all four technology areas. Relative priorities were assigned to all research needs based on a high/medium/lowpriority basis. In addition, representative levels-of-effort were tentatively identified for each research need. The generic needs are discussed in Section 3.1 and the specific needs in Section 3.2. Potential performers of the recommended research are identified in Section 3.3.

An overview of the role of geosciences in the assessment, exploration, and development of geothermal energy resources is provided in Appendix B. This overview is intended to illustrate the far-reaching implications of geoscience data in this area and to reveal why the geothermal environment poses many special problems and 
unknowns for which information and technology borrowed from the petroleum and minerals industries have not been adequate.

\subsection{Generic Research Needs and Priorities}

Four high-priority "across-the-board" research issues were singled out as areas where federal funds could make substantial contributions to geothernal energy development and to the conduct of relevant research. These areas are:

- Geoscience Case Studies

- "Scientific Drilling"

- Information and Technology Transfer

- Improved Research Coordination.

Projects in any of these areas would have the effect of funding a number of the specific research topics detailed in Section 3.2. At the same time, progress appears to be difficult to obtain in each of these areas for a variety of reasons (including technical and federal policy reasons).

- Geoscience case studies. One or more selected geoscienceoriented case studies similar to that sponsored by DOE at Cerro Prieto would be extremely valuable in advancing the understanding of geothermal systems. Possible sites for these studies would include The Geysers (where there is an extensive history of production and data gathering), Roosevelt Hot Springs, UT, Steamboat Springs, NV, and Coso Hot Springs, CA.

One of the problems in formulating and making public case studies on areas in the U.S. is the proprietary nature of much of the industry-developed data. Recourse has been taken to the study of foreign resource areas, where a more complete data package is generally available which can be put into the public domain. However, it is recommended that the federal agencies that fund geothermal $R \& D$ make a considerable effort to find an acceptable way to work with industry to generate and publish case studies on geothermal resources within the U.S. There has been no significant attempt to do this since DOE's Industry Coupled Program, a cost-shared exploration program with industry, was phased out. 
The effort needed here does not entail a single laboratory or other group working with industry to perform and publish a study on individual facets of geothermal development, valuable though such contributions are in their own right. It appears, instead, that a more comprehensive joint industry/federal study program is needed, the implementation of which will require initiation and coordination with industry at a high level within DOE and/or the USGS.

- "Scientific drilling". There are no known geothermal sites in the U.S. or the world where drilling has been deep enough to intersect the region of interaction between an igneous heat source and its hydrothermal system. In fact, there have been few holes drilled in U.S. geothermal systems except for industry's purposes of discovery, reservoir confirmation, and production or injection testing. It is strongly suggested that moderate-depth and deep drilling for scientific purposes at scientifically-selected sites is necessary to collect the data needed to derive valid and useable models of geothermal systems. Funding $f_{1} r$ such drilling is recommended, even if on a year-to-year basis. Current plans for deep drilling by the Continental Sclentific Drilling Project would provide some useful data, but these data are limited in scope at present by a desire to drill into a magma body. of more importance to the geothermal community as a whole would be deep drilling into the roots of a hydrothermal system. It should also be emphasized that useful drill holes would not have to be deep ones, since the objective would simply be to drill for scientific purposes rather than for only sitespecific development purposes. The ability to obtain the valuable data sought in this way will depend on the development of new and improved downhole instrumentation (which is discussed elsewhere in this report).

One approach to minimizing special expenditures for such drilling would be for federal agencies to cost-share drilling of planned industry wells or to fund extension of existing or planned industry wells.

- Information and technology transfer. This is regarded as a vital activity requiring a strong and sustained commitment. In addition to published technical reports and journal articles by the various federally-funded agencies working on geothermal projects, information dissemination through workshops is recommended, particularly since this offers the opportunity for interaction between presenters and recipients of information. A critical role in this area is played by the Geothermal Resources Council (GRC), especially in terms of its annual conferences and associated hard-copy transactions which often contain interim progress reports on $R \& D$ projects not available elsewhere. Funding difficulties are threatening the GRC's continued functioning and some type of federal utilization/support of the GRC would be appropriate and very valuable. The National Technical Information 
Service (NTIS) within the Department of Commerce was also recognized as an important information dissemination mechanism that is unter-funded.

- Improved research coordination. Given the range of federal agencies sponsoring research in this area, the multiplicity of national laboratcries, universities, and other contractors performing the research, and the basic nature of much of the research, there is a need to improve research coordination.

There are important research topic areas that are being supported by a number of federal interests apart from the geothermal program. These include the several programs concerned with high-leve1 and low-level nuclear waste and toxic waste disposal and isolation; the petroleum and minerals industries and the several federal agencies that support their research; and various other environmental protection programs. It is believed that improved coordination of efforts is warranted to maximize the benefits of federal research expenditures in these areas. Noteable research areas are basic geochemical research, basic rock properties research, and hydrological/reservoir engineering modeling.

These four generic research needs were ranked on a high/medium/low-priority scale and they were each assigned a level-of-activity in terms of federal expenditures required. The expenditure ranges are:

Level of Activity

High

Medium

Low
Federa1 Expenditure (\$M)

$$
\begin{array}{r}
>1.0 \\
.2-1.0 \\
<.2
\end{array}
$$

The results of this evaluation are shown below.

Generic Research Need

- Geoscience Case Studies

- "Scientific Drilling"

- Information and Technology Transfer

- Improved Research Coordination
Priority

High

High

High

High
Level of Activity

Medium

High

Low

Low 


\subsection{Specific Research Needs and Priorities}

As mentioned, the Panel's approach to organizing the discussion of research needs was to e:stablish major technology areas concerned with geothermal energy exploration and development that rely heavily on geoscientific data and techniques. Four such logical areas were identified, corresponding to the major geoscience-related activities engaged in by a potential. resource developer. Arranged in order of importance in terms of needed research, these are:

- Reservoir Engineering

- Resource Exploration and Reservoir Definition

- We1l Drilling, Completion, and Stimulation

- Environmental Monitoring and Control.

Within each of these four technology areas, significant research needs for assisting industry in addressing the types of problems outlined in Appendix $B$ were identified and prioritized. All of the technical research needs identified were determined to require a lead federal role, except for a $\mathrm{f} \in \mathrm{w}$ environmental-related research needs which were judged to be the province of industry and require a federal role consisting only of monitoring industry activities.

The four technology areas were prioritized in terms of research need as mentioned above. (The discussions of these areas in this report are arranged in this order.) For each of the technology areas, the research needs were prioritized into high-, medium-, and low-priority groups and they were also prioritized within each priority-group on a $1,2,3 \ldots$ scale of higher-to-lower priority. A relative leve1-ofactivity was assigned to each research item, reflecting the federal expenditures required to adequately address 
the research. As for the generic research needs (see Section 3.1), the high, medium, and low levels of activity refer to the following expenditure ranges:

Level of Activity

High

Medium

Low
Federal Expenditure (\$M)

$$
\begin{aligned}
>1.0 \\
.2-1.0 \\
<.2
\end{aligned}
$$

\subsubsection{Reservoir Engineering}

Exhibit 2 identifies the prioritized research needs for reservoir engineering. The goal of reservoir engineering is to determine reservoir productivity, longevity, and optimum strategies for mining the heat. Accurate information regarding current and future reservoir performance is vital in order for the developer to predict the long-term viability of a project and, consequently, to convince investors that such a project is a sound financial venture. However, by the time the first few production wells are drilled into a geothermal reservoir, there is usually still an unclear picture of the location of the reservoir boundaries, both laterally and with depth, and there are still substantial questions about the variability of reservoir fluid phase (vapor versus water), temperature, pressure, chemistry, and geohydrology. Even after substantial drilling, some or all of these parameters may remain unknown. For example, no one today knows the true extent of The Geysers steam field in California, even though it is the most thorough1y drilled and biggest producing field in the world.

Reservoir engineering as a discipline arose in the petroleum industry in response to the need to understand and predict, from a 
FEDERAL RESEARCH NEEDS, PRIORITIES, AND LEVELS OF ACIIVITY: RESERTOIR ENGINEERING

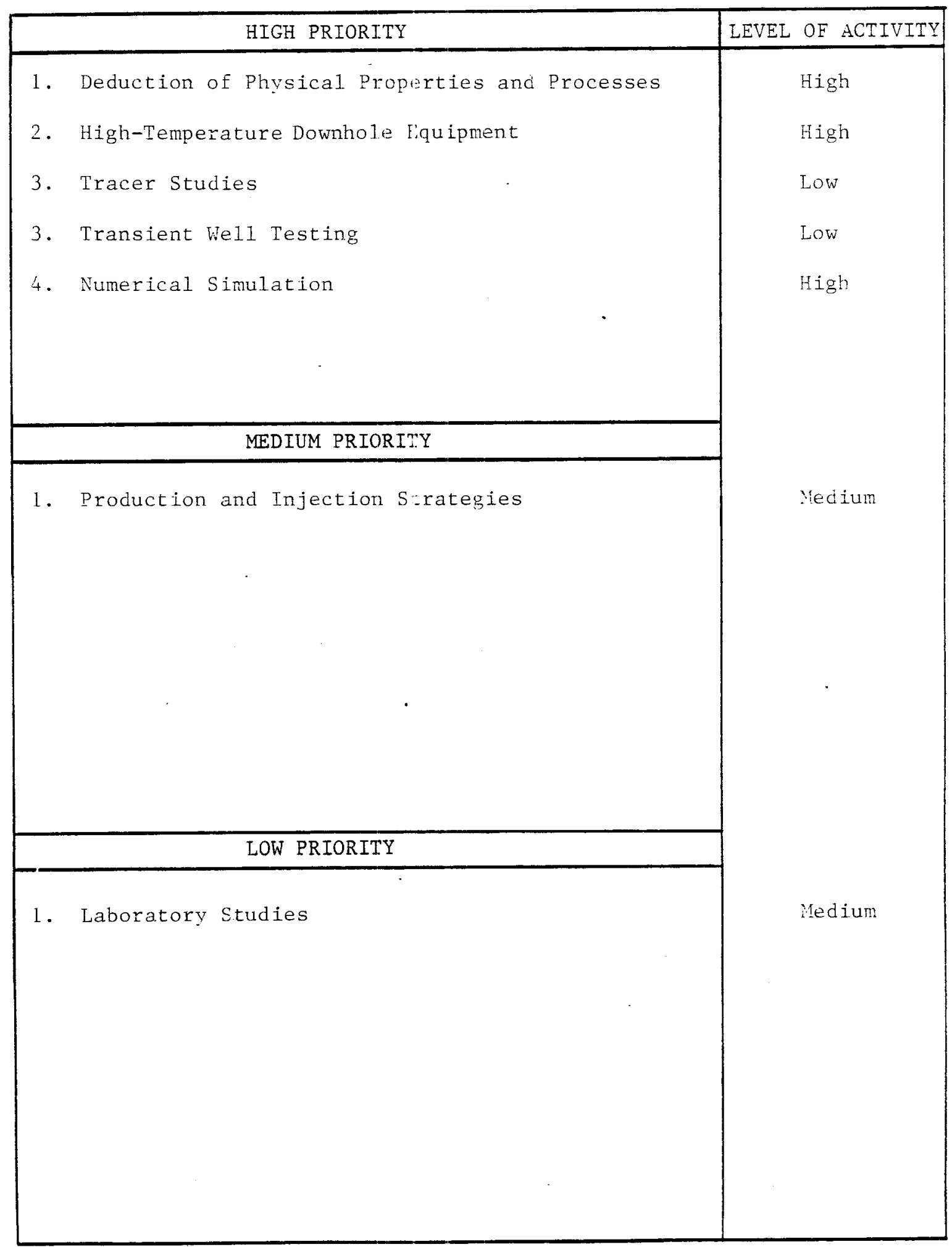


limited number of wells, the production characteristics of a petroleum reservoir. Certain aspects of the discipline also evolved independently within the groundwater hydrology community. In these scientific fields, a fundanental assumption was made early on that the petroleum reservoir and groundwater aquifer both consisted of fluids contained within natural pore spaces in the rock which were uniformly distributed, i.e., that the fluid flow was intergranular. This is a good assumption for petroleum and groundwater engineering, but not for most geothermal environments. Most geothermal reservoirs consist of both intergranular porosity/permeability and porosity/permeability along discrete fractures. The inclusion of such discrete fractures greatly increases the mathematical complexity of numerical modeling and well-testing interpretation schemes. It has only been within the past decade that the more complex problems of fracture flow have even been attempted in a three-dimensional model. Federal research on such problems has been sponsored mainly for nuclear waste isolation purposes, with some support from the geothermal energy program.

The ability to adequately predict the future production characteristics of a geothermal reservoir remains severely restricted. Techniques need to be developed for both data collection and data interpretation in terms of geology, geochemistry, geophysics, hydrology, and geohydrology; these techniques are also needed for exploration and reservoir definition and are identified in Exhibit 4 in Section 3.2.2.4. It is clear that further significant $R \& D$ is needed to enable potential developers to confidently predict reservoir performance and manage the reservoir for optimum long-term energy production. 


\subsubsection{Deduction of Physical Properties and Processes}

At the heart of all exploration work within and adjacent to a geothermal system and of a11 reservoir engineering work is the development of an accurate conceptual model of how the reservoir works--where the fluids come: from, how they are heated, what effects production and injection have, the subsurface configuration of porosity and permeability, and other technical issues. The reliability of quantitative predictions of reservoir performance, productivity, and longevity is directly related to the degree to which the conceptual reservoir model represents reality. At the present time, there are no satisfactory conceptual models for any of the known geothermal reservoirs. A great deal of work remains to be done to increase our level of sophistication in developing models and understanding reservoirs.

- Mechanism of production processes. Production involves migration of fluid along pathways to the borehole. Along the way, the fluid may be chenically altered, it may lose or gain heat, or it may change phase. The mechanism of production is not simple and both theoretical work and in situ measurements will be required to form an adequate understanding of these processes.

- Deductions from physical and chemical data. The complete suite of geological techniques (geologic mapping, stratographic/lithologic studies, structural studies, age dating, etc.), geochemical techniques (chemical geothermometry, studies of the distribution and zoning of major, minor, and trace elements, hydrothermal alterations of reservoir rocks by thermal fluids, etc.), geophysical techniques (surveys and interpretation to determine subsurface values and their variations throughout the reservoir for electrica1 resistivity, density, magnetic properties, seismic properties, thermal conductivity, etc.), and geohydrological techniques (well testing, modeling, mapping piezometric surfaces) are all fruitfully applied to help determine the physical and chemical properties of the reservoir for input to the conceptual model and to successfully site production and injection wells. There is a need for research to 
determine how to best apply these methods to reservoir engineering problens and to determine what information concerning properties and processes can be deduced from the physical and chemical data obtained.

\subsubsection{High-Temperature Downhole Equipment}

As discussed in Section 3.2.2.4 under "Resource Exploration and Reservoir Definition", the same basic geoscience techniques are used both for exploration and reservoir engineering. The primary driving force for developing new or improved techniques will be exploration and reservoir definition needs, since these are the first stages in the resource assessment and development process. Reservoir engineering commences after the decision has been made to proceed with resource development and is an on-going interest throughout the life of the energy project. Assuming that adequate geoscience techniques are made available to facilitate exploratory activities, the special needs in reservirir engineering center on high-temperature downhole instrumentation (including logging equipment, log interpretation, and fluid sampling).

Existing downhole temperature and pressure measuring tools and fluid samplers do not perform adequately above about $200^{\circ} \mathrm{C}$ in geothermal applications. Since the high-temperature equipment needs for reservoir engineering are essentially the same as for geothermal drilling, the problems and research needs discussed under "High-Temperature, High-Pressure Borehole Instrumentation" (Section 3.2.2.3) also apply here.

\subsubsection{Tracer Studies}

Chemical tracers are sometimes added to injected waters and 
monitoring is then carried out in adjacent wells in an attempt to establish the presence of fluid communication between the we1ls. In the usual case, the tracer is not detected in other wells and the experimenter does not know whether there is no fluid communication or whether the tracer has been removed from solution through chemical interaction or absorption/ion-exchange with the reservoir rocks. Tracer studies have been less than satisfactory as applied so far to geothermal problems.

There are three types of "breakthrough" that can occur between geothermal wells. The first occurs if a pressure transient is observed in one well as a result of testing in a second well (see "Transient Well Testing," Section 3.2.1.4). This means that a pressure change has propagated through the reservoir fluid to the second we11. The second type of breakthrough is an actual breakthrough of a fluid pocket which started at one well and traveled to the second. Detection of such fluid breakthrough is the objective of tracer tests. The third type of breakthrough is thermal breakthrough, where not only does fluid travel between wells, but it does so sufficiently quickly that it is not heated to reservoir temperatures along the way. Obviously, pressure breakthrough would normally be experienced first, fluid (tracer) breakthrough some time later, and actual thermal breakthrough even later. Thermal breakthrough can be a major problem at a geothermal well field. Interpretation of tracer studies is often aimed at predicting thermal breakthrough and averting it before it happens.

- Tracer selection. It is important in tracer studies to have available tracers that (a) are easy to detect in small quantities at remote sites, (b) undergo no chemical or absorption/ion-exchange reactions with native reservoir rocks and 
fluids, (c) are environmentally acceptable, and (d) are inexpensive. No tracers exist today that adequately meet all of these criteria.

- Development of tracer techniques. There are two basic tracer techniques. Tracer can be injected in one site and monitored at a second site or it can be injected and then withdrawn at the same site. The first method has recelved limited geothermal application to date, not all of which has been useful. Better techniques to interpret tracer concentration versus time at remote sites in terms of the nature and geometry of the flow path are needed.

In the second method, tracer is injected into a well continuously or as a slug and then measurement is made of tracer concentration versus time in the fluid as the well is produced. DOE has a currently-funded program to try to develop ways to use such "huff-puff" tracer data. The method shows promise for mapping fluid flow in the near-wellbore environment.

- Effects of tracers on future studies. Care must be taken that introduced chenical tracers do not interfere with future geochemical studies of the reservoir. Tracers can modify the chemical environment sufficiently to render other chemical studies invalid. Better methods for determining likely effects of tracers are needed, which will probably be based mainly on the chernical modeling techniques mentioned above.

\subsubsection{Transient Well Testing}

Detailed and accurate measurement of pressure, temperature, dissolved gases, and other chemical parameters are made during flow or injection testing of geothermal wells. These measurements can permit the determination of productive well flow rate, enthalpy, 1ikely longevity, temperature and pressure decline with time, and other useful information. A variety of flow conditions can be established to make these measurements and sometimes a combination is useful. A single production well can be flowed naturally or pumped at various rates and an injection well can receive injected waters at various rates. By producing or injecting at one well site while monitoring temperature, pressure, and fluid level at a second site, 
interference tests are made.

For several decades in the early and middle parts of this century, development of these testing techniques took place independently in the groundwater and petroleum reservoir engineering communities. Today, their effors are more united, but much work remains to be done.

For all of these tests, there are essentially two options for measurement: (a) measure temperature, pressure, and flow rate at the surface or (b) measure at least temperature and pressure downhole. Option (a) is easier, but it is often necessary to know the temperature and pressure at the producing horizon. Unless these can be measured downhole, a borehole simulator model must be used. Problems related to this area are discussed under "Drilling Equipment and Techniques" (Section 3.2.3.1) and "Borehole Heat Transmission and Fluid Mechanics" (Section 3.2.3.7).

- Single well tests. From a single well flow test, formation porosity, permeability, temperature, pressure decline, and transmissivity can be measured and the presence or absence of fluid recharge areas or of aquitards can be determined. The presence or absence of wellbore damage (inhibition of permeability near the wellbore, usually due to drilling or completion) can also be determined. Although analysis of data on pressure, temperature, and flow rate versus time is well in hand for porous media (the petroleum environment), more work needs to be done for fractured media.

- Multiple-we11 tests (interference tests). Use of pressure, temperature, and water level data from one or more wells during flow testing or injection testing of a second well can yield information in addition to that available from single well tests. Interpretation of multiple-well tests in porous media is reasonably well understood at present, but that for fractured media still requires more research.

- Multiple-porosity systems. Well testing and interpretation of all types today are based on the assumption of a singlephase fluid. Since gas in a formation can cause substantial changes in the flow of both the liquid and the gaseous phases, effects of having both phases present need to be 
accounted for. Techniques to do so are needed.

- Early characterization of a reservoir. It would be highly useful to industry to have reliable techniques to be able to predict the production characteristics of a reservoir early in its 1ife, when only one or a few wells are available for testing. In addition, because all well tests are expensive and must often be run for days or months to achieve a sufficient level of reliability, early reliable results would be welcome. Comparison of advanced well analysis predictions with operating history is needed. Unfortunately, much of the needed data remain in company files.

\subsubsection{Numerica1 Simulation}

Computer simulation of fluid flow problems has been an important topic of research and technique development for more than a decade now. Impetus has been given to this research from the nuclear waste management, the petroleum production, and the groundwater production sectors, in addition to the geothermal sector. Coordination of the efforts among the USGS and the various federal laboratories working on these problens is needed.

- Development of advanced simulators. At the present state of the art, the more trivial simulation problems such as oneand two-dimensional flow in porous media can be easily handled and little futher work remains to be done on systemwide modeling problems (but see "Tracer Studies", Section 3.2.1.3). Computer models to simulate fluid flow in three dimensions, incorporating both fracture and intergranular permeability, including both liquid and gas phases, and allowing for temperature variations, are, however, still in the developmental stage. Furthermore, the coupling of such advanced models with chemical reaction models (such as those discussed under "Borehole Heat Transmission and Fluid Mechanics," Section 3.2.3.7) is still on the drawing board. If a complete physical/chemical model simulator could be developed, it would have great utility. However, the separate problems of modeling just the fluid flow on the one hand and just the chemical interactions on the other hand are yet to be solved in enough complexity to be truly useful and they each tax even the largest computers. Their integration is still a ways in the future, although it is a rational objective to pursue.

Current reservoir simulator models are esentially of two 
types. The first is the hydrologic model, which has been largely developed by the groundwater hydrologists. It finds application in some of the more simple geothermal systems and is adequate at presient for some of the low-temperature and basin-controlled geothermal resources. The second type is the more complex and more complete approach of petroleum reservoir engineers. These are the models that are currently being improved to handle multi-dimensional, multi-phase, nonisothermal flow in fractured and porous media. These models have not yet been developed to the point of being geologically realistic except for simple situations, nor is the modeling in more detail than on a geothermal system-wide basis. Much more fruitful work remains to be done here.

- Equations of state. As stated under "Borehole Heat Transmission and Fluid Mecharics" (Section 3.2.3.7), the physical properties of the water-steam system at varying chemical compositions and ais functions of temperature and pressure have not been measured. Only the pure water-steam system is well known. The addition of dissolved chemical species and gases modifies the physical properties to an extent that must be guessed at today. It is important to know the equations-of-state for geothermal fluids because such equations-of-state Eorm an important part of all reservoir numerical simulators. Basic laboratory measurements of equations-of-state need to be carried out.

\subsubsection{Production and Injection Strategies}

Geothermal production, whether of high-temperature or lowtemperature resources and whether in hydrotherma1, hot dry rock, or magma resources, is essentially a process of mining heat from the rock. It is easily shown that, even in hydrothermal systems, the majority of the heat is in the rock. However, rock has such a low thermal conductivity that it gives up its heat very slowly to fluids in contact with it along fractures and pores. Producing a system at too high a rate could result in removal of the heat near the fractures and pores too quickly, with the result that the production temperature drops below minimum requirements. An optimum strategy is, therefore, needed to mine maximum heat at lowest cost and with minimum environmental effects. 
- Production strategies. There are essentially no criteria for determining the spaling of production wells beyond the need to eliminate interference among wells. Well spacing is largely determined by trial and error. Clearly, better methods to do this are needed. These will undoubtedly rely heavily on development of an adequate conceptual reservoir model and upon sophisticated numerical modeling programs.

- Injection strategies. Injection of spent geothermal fluids back into the ground is a practice that is becoming more extensively used to maintain reservoir pressure, control the recharge process, and prevent subsidence. One important criterion for injestion well siting is to avoid shortcircuiting between j.njected fluid and production wells. More research is needed along these lines.

- Energy conversion considerations. Any given production/injection scheme must not only optimize the mining of heat while minimizing cost, but must also minimize adverse changes in produced fluid characteristics (e.g., temperature, pressure, fluid phaise) with respect to power plant requirements. Scaling and corrosion must also be considered when devising fluid management procedures.

\subsubsection{Laboratory Studies}

Neither the physical nor chemical properties of reservoir

rocks or fluids are well understood. Laboratory studies of the physical properties of reservoir rocks are needed in addition to the basic data on chemical thermodynamics discussed elsewhere. In addition, scale models of geothermal systems have potential to contribute to this understanding.

- Physical and chemical properties. The need for measurement of physical and chemical properties of rocks and fluids is mentioned in several contexts in this report(see Sections $3.2 .1 .1,3.2 .1 .5,3.2 .3 .4$, and 3.2 .3 .7 ).

- Development of scale models. Scale models form an alternative to the use of numerical computer models for determining the behavior of geothermal systems, but they have not been much used to date. Models of fluid flow might be especially instructive. Scale models might also be useful in predicting geophysical responses to various geothermal systems. 
- Comparison and evaluation of data from different sources. A great deal of thermodynamic data exists today that is only margina1ly useful because it has not been checked or made internally consisteat. A fairly small effort to put all available data sources on a common basis is needed.

\subsubsection{Resource Exploration and Reservoir Definition}

Exhibit 3 identifies the prioritized research needs for resource exploration and reservoir definition. These activities are aimed at locating geothermal resources and at defining such resources when found. A developer begins by selecting a certain geologic environment or geographic area in which to explore. Exploration techniques that are designed to solve specific geological problems are applied to progressive within the area for further exploration work (see Exhibit B-2 in Exhibit B). He finally selects one or more sites for test drilling. If the results of this drij.ling are encouraging, the developer will further explore the site using tools that yield progressively more detail. Several wells may be required before a productive reservoir confirmation well is drilled or the developer decides to abandon the site. If a successful confirmation well is drilled, further drilling is usually undertaken with concurrent gathering of more exploration data to guide selection of drill sites.

The exploration and reservoir definition process uses a full range of geological, geochemical, and geophysical tools, as discussed further below. Almost none of these tools is presently optimum for geothermal exploration because they have been developed by the petroleum and minerals industries for their specific problems. These tools are currently being utilized by the geotherma1 industry due to 
EXHIBIT 3

FEDERAL RESEARCH NEEDS, PEIORITIES, AND LEVELS OF ACTIVITY:

RESOLRCE EXPLORATION AND RESERVOIR DEFINITION

\begin{tabular}{|c|c|}
\hline HIGH PRIORITY & LEVEL OF ACTIVITY \\
\hline 1. Joint Interpretation of luata & Low-Yedium \\
\hline $\begin{array}{l}\text { 1. Conceptual Nodel for Exterisional Geologic } \\
\text { Environment }\end{array}$ & Low-íedium \\
\hline $\begin{array}{l}\text { 1. Conceptual Model for Subdictive Geologic } \\
\text { Environment }\end{array}$ & Low-Yedium \\
\hline 2. Development and Testing of New/Improved Techniques & Low-iedium \\
\hline MEDIUM PRIORITY & \\
\hline $\begin{array}{l}\text { 1. Conceptual Model for B.imotal Rhyolite/Basalt } \\
\text { Geologic Environment }\end{array}$ & Low-iledium \\
\hline LOW PRIORITY & \\
\hline $\begin{array}{l}\text { 1. Conceptual Model for "Hot Spots" Geologic } \\
\text { Environment }\end{array}$ & Low-Yedium \\
\hline $\begin{array}{l}\text { 1. Conceptual Hodel for Intracratonic Basins Geologic } \\
\text { Environment }\end{array}$ & Low-Medium \\
\hline $\begin{array}{l}\text { 2. Conceptual rodels for Other Geologic Environments } \\
\text { (e.g., passive margins, overthrust) }\end{array}$ & Low-Medium \\
\hline
\end{tabular}


the lack of tools tailored to the needs of the geothermal explorer/developer.

The essential characteristics of geothermal systems which set them apart from petroleum resources are the source of the inappropriateness of much of the exploration and reservoir definition technology transferred from the petroleum industry, including conceptual modeling of resources. These characteristics include the deep, hard-rock environment, the fractured nature of formations, the high temperatures, the chemically-complex fluids, and the uncertain origins and recharge controls of reservoir fluids. In addition, longterm field experience comparable to that existing in the petroleum industry does not exist from which relatively reliable empirical or intuitive insights can be brought to bear during exploration.

Resource exploration and reservoir definition take place within the context of certain types of geologic environment. Six geologic environments were identified in terms of geothermal interest (five specific types of environment and an "other" category). The research needs in this area center around developing conceptual models for these geologic environments, developing new or improved geological, geochemical, and geophysical techniques, and integrating existing and new data for the purpose of joint interpretation.

\subsubsection{Joint Interpretation of Data}

Geological, geochemical, geophysical, and hydrological data need to be collected for use in interpretive models. Some of these basic data may be available in the public domain, but federal funds for collection of new data are needed. These data need to be 
combined with earth science data obtained by drilling of scientific research holes (see Section 3.1) and interpreted in an integrated fashion. This will involve development of new interpretation techniques. The petroleum industsy is currently working on schemes for joint interpretation of oil exploration data and these efforts show great promise. A similar effort for the particular types of data relevant to geothermal exploration is needed.

\subsubsection{Conceptual Model for Extensional Geologic Environment}

In the U.S., this environment is typified by: (a) the Basin and Range geologic province, where extension of the earth's crust has produced a regime of listric faults (faults that dip steeply near surface but flatten to near horizontal at depths of 2 to $6 \mathrm{~km}$ ) that separate uplifted nountain blocks from downdropped valley blocks and control the emplacenent of intrusions in the earth's crust and the plumbing systems of geothermal resources; and (b) the Imperial Valley of southern California, where the crust is being stretched due to spreading and transform faulting along the East Pacific Rise, a plate tectonic spreading center that comes onto the continent in The Gulf of California and underlies a large area whose exact boundaries are unknown. Igneous rocks in these areas usually include both basalt and more acidic species, usually rhyolite. Elsewhere, Iceland sits astride The Northern Mid-Atlantic Ridge, a similar spreading center, where the volcanism is all basaltic in composition. 
There is a need to develop a better understanding of the distribution of high-level thermal anomalies in terms of:

- Nature of the heat source

- Crustal structure

- Nature of faulting activity

- Hydrologic setting

- Mechanism and rate of extension and effect on the thermal regime.

\subsubsection{Conceptual Model for Subductive Geologic Environment} Where oceanic crustal plates, which are continually being lengthened due to creation of new crust at spreading centers, impinge on continental plates, the oceanic plate is generally thrust under the continental plate. Partial melting of the oceanic plate takes place in selected spots and the melts so generated rise, through buoyancy, into the crust. If they rise close enough to the surface, they can interact with groundwater and create hydrothermal systems, or form potential hot dry rock or magna resources. In the U.S., the volcanos of the Cascades Rarnge and of the Aleutian Islands have their origin in such processes. Elsewhere, volcanic activity in Mexico, Central American, South America, parts of Japan, Italy, New Zealand, as well as other countries, takes place in subductive environments. The igneous rocks are typically of andesite composition.

There is a need to develop a better understanding of the following features of the subductive environment:

- Nature of the heat source

- Crustal structure

- Nature of faulting activity 
- Hydrologic setting.

A good approach would be the conduct of comparative studies (including foreign sites) to obtain a better understanding of andesite systems, especially their evolution and the relation of hydrothermal systems to intrusives.

\subsubsection{Development and Testing of New/Improved Techniques}

There is a pressing need for the development of new techniques and approaches to exploration - both exploration for geothermal systems and, once a system is found, exploration within geothermal systems. This need extends both to development of new field techniques and instrumentation and to new or improved methods of interpretation. The same basic techniques are used both for exploration/reservoir definition and for reservoir engineering (see "Reservoir Engineering", Section 3.2.1), although the high-priority needs for reservoir engineering center on high-temperature downhole instrumentation. A list of perhaps the most important techniques in terms of potential contribution to geothermal development and those most in need of further research and development is given in Exhibit 4.

\subsubsection{Conceptual Model for Bimodal Rhyolite/Basalt} Geologic Environment

In the U.S., there are areas characterized by episodic rhyolitic and basaltic volcanism where the rhyolitic episodes can be explosive in nature and can expel very large volumes (tens to hundreds of cubic kilometers) of magma. Collapse of the rock above the emptied magma chamber produces circular caldera features and 


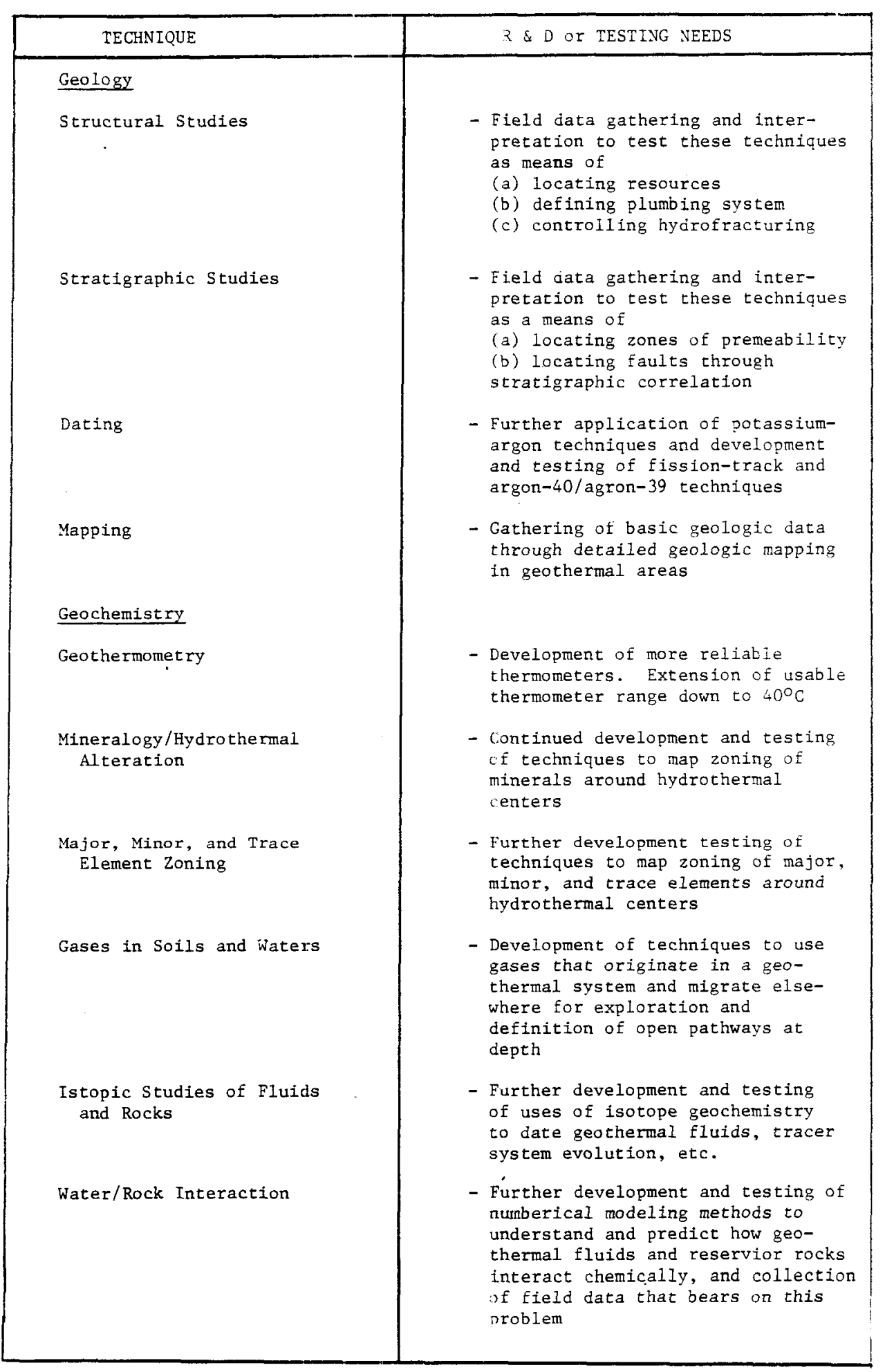




\begin{tabular}{|c|c|}
\hline TECHNIQUES & $R \& D$ or TESTING NEEDS \\
\hline Geophysics & \\
\hline Magnetotellurics (MT) & $\begin{array}{l}\text { - Further development of efficient } \\
\text { 3D computer algorithms and inter- } \\
\text { pretation techniques }\end{array}$ \\
\hline Audiomagnetotellurics (AMT) & $\begin{array}{l}\text { - Development of a field worthy } \\
\text { tensor AMT system and of inter- } \\
\text { pretation techniques }\end{array}$ \\
\hline Electromagnetics (EM) & $\begin{array}{l}\text { - Development of efficient } 2 D \text { and } 3 D \\
\text { computer algorithms and interpre- } \\
\text { tation techniques }\end{array}$ \\
\hline Self-Potential (SP) & $\begin{array}{l}\text { - Further development of interpre- } \\
\text { tation techniques and of under- } \\
\text { standing of the basic mechanisms } \\
\text { responsible for the phenomenon }\end{array}$ \\
\hline Seismic & $\begin{array}{l}\text { - Testing of high-resolution, 3D } \\
\text { seismic reflection techniques in } \\
\text { one or two selected geothermal } \\
\text { environments } \\
\text { - Further testing of the uses of } \\
\text { P- and s-wave delay and attentuation } \\
\text { in and near magma bodies } \\
\text { - Further testing of the potential } \\
\text { uses of microseismic technicues } \\
\text { for locating geothermal areas }\end{array}$ \\
\hline Heat Flow & $\begin{array}{l}\text { - Gathering of basic heat flow, } \\
\text { thermal gradient, and thermal } \\
\text { conductivity data in geothermal } \\
\text { environments }\end{array}$ \\
\hline $\begin{array}{l}\text { Well Logging (also especially } \\
\text { for reservoir engineering and } \\
\text { for well drilling, completion } \\
\text { and stimulation) }\end{array}$ & $\begin{array}{l}\text { - Calibration of available well } \\
\text { logs in the geothermal environ- } \\
\text { ment } \\
\text { - Further development of the bore- } \\
\text { hole televiewer log } \\
\text { - Further development of high- } \\
\text { temperature logs, operable to } \\
350^{\circ} \mathrm{C} \\
\text { - Development of interpretation } \\
\text { techniques suitable for geo- } \\
\text { thermal environments }\end{array}$ \\
\hline Data Gathering & $\begin{array}{l}\text { - Gathering of basic geophysical } \\
\text { data through field surveys in } \\
\text { geothermal areas }\end{array}$ \\
\hline
\end{tabular}


systems of steep faults that can form the plumbing system for hydrothermal resources. Ancient calderas as well as modern ones are both recognized. The Valles Caldera in New Mexico and Long Valley in California are examples of this geologic environment.

of special interest is leveloping a better understanding of:

- The interaction of the hydrothermal system with the heat source

- The generation and evolution of the system (both magmatic and hydrothermal portions).

\subsubsection{Conceptual Model for "Hot Spots" Geologic Environment}

In a number of places, typified by Hawail, volcanic activity appears to result from the crust moving above a "hot spot" in the mantle that creates melis which rise into and through the crust. In the ocean areas, the nagmas are generally all basaltic. There is speculation that the Snake River Plain in Idaho has resulted from movement of the North American continental plate across a mantle hot spot which now underlies Yellowstone National Park. Hot spots are believed to have created marly of the volcanic islands, now atol1s, in the Southern Pacific Ocean, most of which have long since cooled due to their great age.

Although this geologic environment is not common and is of low priority in terms of modeling, the U.S. Geologic Survey should continue its research program in Hawaii.

\subsubsection{Conceptual Model for Intracratonic Basins Geologic Environment}

Intracratonic basins are structural basins developed on the continent through geologic processes that lead to downwarping or down- 
faulting of the surface. The subsidence process generally takes place over millions or tens of millions of years and its pace is matched by infilling of the basin with erosional debris from nearby highlands. In some of these basins, the deposited sediments become consolidated (indurated) with time and form hard rock, whereas in others, the sediment remains relatively unconsolidated. Most of these basins in the U.S. have been extensively explored for petroleum and drilling associated with this exploration has discovered thermal waters in places. Examples of geothermal resources associated with basins in the U.S. incluce the geopressured resources of Texas, Louisiana, California, and elsewhere and the thermal waters of the Williston basin and surrounding areas in North Dakota, South Dakota, and Wyoming. Such basin areas supply large quantities of thermal waters for direct application. Space heating applications of thermal waters of the Paris Basin in France are also a well known example.

The structural and thermal evolution of intracratonic basins is of special interest. Research in this area should be coordinated with studies of petroleum maturation.

\subsubsection{Conceptual Models for Other Geologic Environments}

There is a number of other geothermal environments in the U.S. which have the possibility of containing thermal waters. The Overthrust Belt of the Rocky Mountain region is one such area. The radioactive plutons of the Atlantic Coastal Plain are another example. Although a certain amount of background research work may be merited on these environments, they presently appear to be capable of far less contribution to the energy needs of the U.S. than the pre- 
vious1y-identified geologic environments. Thus, no specific research work has been identified at this time.

\subsubsection{Well Drilling, Completion, and Stimulation}

Exhibit 5 identifies the prioritized research needs for well drilling, completion, and stimulation. Drilling is a major cost item in geothermal development, accounting for approximately half of total development costs. It is, therefore, extremely important that well sites are properly chosen and that cost-effective drilling and completion technology is employed.

Current drilling technology for high-temperature geothermal resources is that developed almost exclusively by the petroleum industry. Due to the high fluid flow rates required for most geothermal utilization systems and the depth of most resources, large well diameters and correspondingly large drilling equipment is required. The geothermal environment is quite different from the petroleum environment, especially in terms of higher temperature, more corrosive fluids, and generally harder rocks. For example, the minimum temperatures required for commercial exploitation of geothermal energy for the generation of electricity generally are greater than the maximum temperatures attained in petroleum reservoirs. Modifications to current drilling technology are indicated.

We11 completion consists of processes designed to ensure flow from selected intervals in the we11. Solid casing is set in the we11, with the bottom of the casing above the producing section and 
FEDERAL RESEARCH NEEIS, PR RORITIES, AND LEVEIS OE ACTIVTTY: WELL DRILLING, COMPLETION, AND STIMULATION

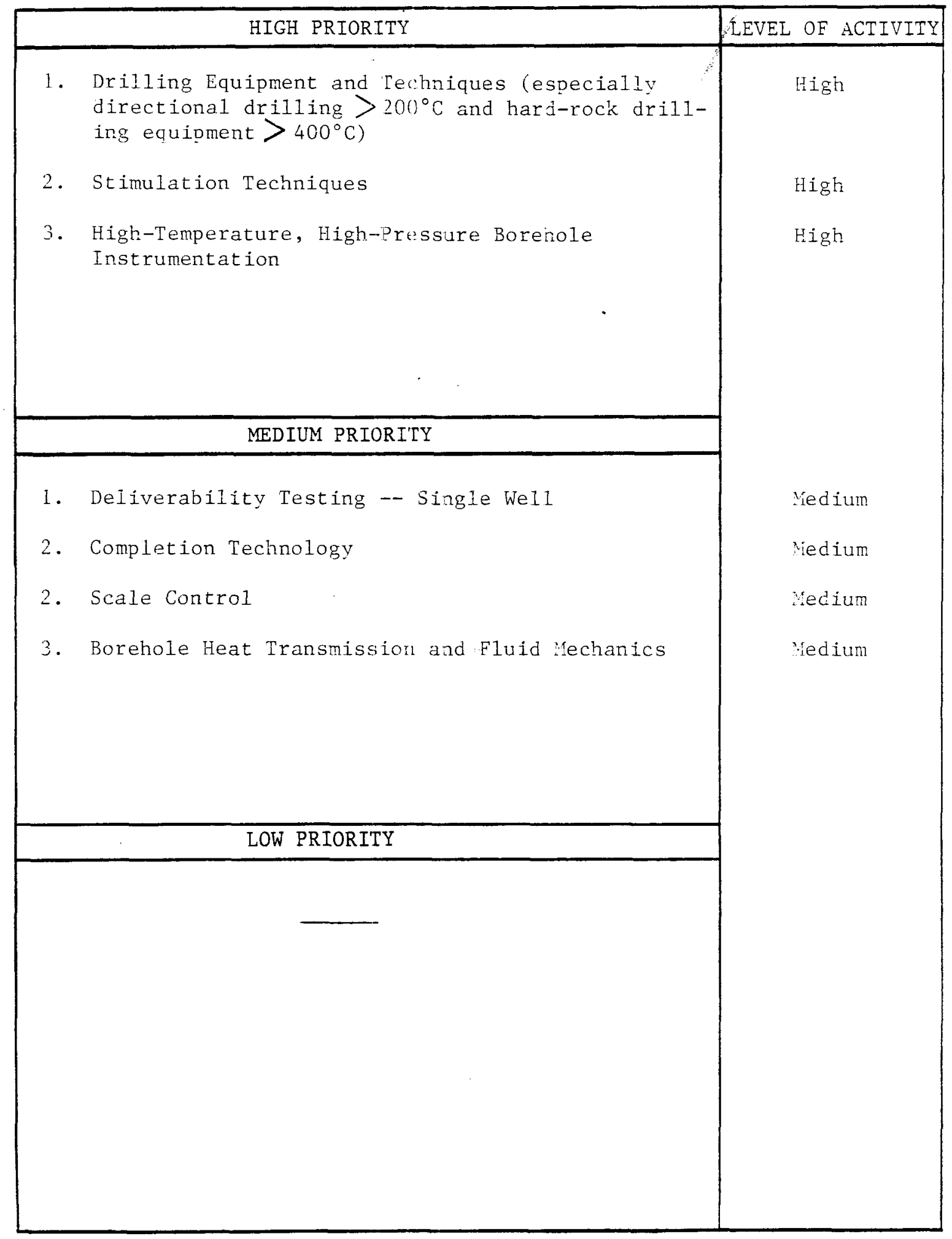


either a slotted liner hung down through the producing interval or a barefoot completion with no casing through the production interval (as is done at The Geysers). If the reservoir has intergranular porosity and permeability and is in a liquid-dominated system, solid casing may be set through the production zone and then perforated. The well is then cleaned of all drilling fluid and it may be surged to help remove drill chips and fluid lodged in the aquifier. Completion techniques are necessarily different in geothermal wells than they are in petroleum wells. These differences arise from the generally higher temperature: and much higher flow rates in geothermal wells compared to petroleum wells and the low bottom-hole pressure in a vapor-dominated reservoir.

Most geothermal wells must be stimulated to initiate flow and we11-developed techniques are available for this. However, if the maximum flow rate is still not large enough to make the well a good producer, more exotic and sophisticated stimulation techniques may be required. These include hydrofracturing, chemical stimulation (generally with acid), or explosive stimulation. These types of stimulation techniques are quite expensive and they often do not work. Development of better stimulation techniques is warranted.

\subsubsection{Drilling Equipment and Techniques}

Most geothermal drilling takes place using conventional or modified petroleum exploration equipment. The depths of many hightemperature resources (5,000 to 12,000 feet) and the large flow rates required of a productive well (250,000 to over $1,000,000$ pounds/hour) place a requirement of large diameter (6-10 inches) on the completed 
we11. This requires large drilling rigs. Modifications to drilling rigs, muds, casing, and other $r$ associated equipment must also often be made because of the high teriperatures encountered $\left(200-300^{\circ} \mathrm{C}\right)$ and the corrosive chemical environment. Much of the equipment developed for drilling in the cooler, relatively soft-rock petroleum environment is inadequate for geothermal drilling. This includes downhole drill motors, drilling fluids, casings, open-hole and cased-hole packers, and other components of the drilling system. Drilling for low-temperature, direct-application geothermal resources is usually done using conventional water well equipment and does not cause a severe problem.

- Hard rock drilling at high temperatures. Drilling of hard rock (granites) requires more expensive drill bits and generally sturdier equipment than does drilling of softer rock (shales, sandstone, limestones). Drilling rate in hard rock is lower, increasing ultimate well cost. Research is needed both for improvement of existing equipment and techniques and for development of new rock penetrating methods and equipment. Incremental improvements are being made by the drilling industry today, but these are almost exclusively directed toward petroleum drilling since the economic impetus for the drilling industry to improve geothermal drilling capabilities does not yet exist.

- Tubular goods. Tubular goods include both the drill pipe itself, which rotates the drill bit and through which fluids are pumped into and out of the hole to remove cuttings, and the well casing, which lines the well. Casings serve several functions, including prevention of collapse of the borehole walls, exclusion of unwanted, cooler or chemically objectional fluids from the well, and selective admission of fluids into the well through slotted or screen-type liners. Tubular goods are subject to corrosion and/or failure due to the harsh nature of the environment. For example, the geothermal industry has recently become aware that hydrogen sulfide gas $\left(\mathrm{H}_{2} \mathrm{~S}\right)$ can be responsible for a type of chemical stress failure of tubulars, and the present remedy is an expensive alloy steel that is not even available in the U.S. at reasonable cost. Better materials are needed for tubular goods, and, due to the small size of the geothermal industry, development of such equipment is not likely to be accomplished by industry alone. 
- Directional control. Drilling pads are expensive to prepare, especially in mountainous terrain, so there is impetus to drill several wells from a single site. In order to achieve separation of the well bores and/or to intersect specific target areas that may not be directly below the drill site, directional drilling is often attempted. This always increases costs and often fails. The best directional control at the fastest drilling rate can often be achieved using a downhole drilling motor to rotate the bit or hammer the formation rather than providing rotary power from a surface motor connected to the drill stem. Downhole motors of today have a high incidence of failure in the geothermal environment and none: is adequate at temperatures above about $250^{\circ} \mathrm{C}$. New motors are needed to operate up to $350^{\circ} \mathrm{C}$ or beyond. There is also a need to develop better equipment for monitoring well deviation from the vertical and the direction of horizontal progress during drilling.

- Drilling fluids. Drilling fluids are required to remove drill cuttings from the well and to cool and lubricate the bit. Conventional petroleum drilling fluids are inadequate for many geothermal applications because they break down in the high-temperature, chemically-hostile geothermal environment. In addition, some drilling fluids interact with reservoir fluids and cause precipitation of minerals in the formation adjacent to the wellbore, plugging fractures and pores and leading to diminished permeability and well productivity. Development of drilling muds, foams, and surfactants that are especially tailored to the geothermal environment is needed. Present materials generally begin to fail above about $225^{\circ} \mathrm{C}$ and are largely inadequate above $275-300^{\circ} \mathrm{C}$.

\subsubsection{Stimulation Techniques}

Stimulation is the process of inducing a well to flow at

its maximum (or optimum) production rate. Some stimulation techniques are applied during well completion, but it is the more exotic and costly techniques that are sometimes needed later to make a well into a good producer that are discussed here. There are several different methods of stimulation, each having its own problems and research needs. There is need for a great deal of research to develop lower cost, more reliable stimulation techniques.

- Hydrofracturing. In this technique, water is pumped into the well at a high rate and at a pressure large enough to over- 
come the least principal stress in the rock at the fracturing depth. Once a fracture is started, it is propagated by continued pumping. Sand or other proppant material may be pumped into the fracture along with the water to help keep the fracture open once fluid pressure is reduced. These techniques have been jioneered by the petroleum industry to enhance oil recovery. The problems of their use in the geothermal environment are somewhat different from and more severe than those in the petroleum environment.

One of the problems; concerns the direction and dip of the resulting fracture. At present, there are no reliable methods to control these parameters. Potential methods for doing so involve being able to measure the state of stress in the rock in situ, which is difficult. New technology is needed in these areas. A second problem is concerned with detection and mapping of the fracture that is formed. This is especially critical in development of hot dry rock, where a connection through a fracture system between two wells must be made in order to set up fluid circulation. A third problem is one of availability of appropriate proppants. Fine sand is sometimes used, but it can be rapidly degraded by the hostile geothermal environment. Sintered bauxite, an ore of aluminum, can be used to increase resistance to chemical erosion, but it is expensive. New, cheap proppants are needed.

The petroleum industry has successfully been able to propagate a main fracture, then to plug the end of this fracture to prevent further propagation, and to instead induce subsidiary fractures off the main one in another direction. These techniques have ret with only limited success in geothermal application. Further development is needed.

- Chemical stimulation. Using this technique, a volume of corrosive fluid, one that will react chemically with the reservoir rock and create new fluid pathways, is injected into the formation. A slug of clear waters follows to clean the drill casing, which otherwise could be damaged. After a certain length of time, the well is produced to see if enhanced fluid flow results. This technique shows promise, but further development, based more on chemical considerations of the optimum stimulation fluid and the likelihood of unwanted precipitation or creation of minerals with accompanying volume expansion, is needed.

- Explosive stimulation. Conventional explosives have been used with varying success to stimulate wells in the petroleum environment. There has not been a successful geothermal application to date. One of the problems is the very limited region around the wellbore that can be fractured using conventional explosives. Nuclear explosives could also be employed, but for reasons of cost and potential environmental damage they will probably never be used. Explosive 
fracturing has the lowest potential of the stimulation techniques for geothermal hard-rock applications, except possibly at sites where the perneability needs enhancement only in the near-we11bore vicinity.

\subsubsection{High-Temperature, High-Pressure Borehole Instrumentation}

Heavy muds are often used to apply positive pressure to the formation because of the possibility of blow-out during the drilling of a geothermal well. In addition, the drill fluids are cooled before being pumped down the well and they cool the formation and its contained fluids at depth. Thus, it is usually the case that the productivity, or lack thereof, of a we11 can only be determined by cleaning the well after deilling and by inducing and stimulating geothermal fluid flow. The proper interval(s) to be stimulated and flow tested are usually not known a priori and must be selected. The most useful techniques to do this selection are the geophysical well logging techniques. Such quantities as well diameter, temperature, electrical resistivity, natural radioactivity, induced radioactivity, and seismic velocity are measured in profile down the well in order to determine which intervals have highest porosity, permeability, and appropriate temperatures. These intervals are then selected for flow testing. Other logs such as borehole flow meters and borehole televiewer logs are also used. There is a need to improve both the instrumentation and the data interpretation techniques in these endeavors.

- Improved instrumentation. Geophysical well log instrumentation has been developed and refined by the petroleum industry to a significant extent and that industry continues to make substantial improvements. To date, the geothermal industry has had no recourse but to apply petroleum instrumentation and techniques to geothermal logging problems. There have 
been two major drawbacks to this. One is that the equipment is inadequate at hi.gh temperatures. Neither the electronic components that nust be used downhole nor the electrical cables to carry signals to the surface are adequate at present. The other is that petroleum interpretion techniques do not uniformly apply in the hard-rock, geothermal environment (see next item).

DOE-sponsored resear:ch succeeded in improving materials for electronic componen:s for geophysical well logs, but more work is needed. Both cables and electronic equipment begin to fail above about $200^{\circ} \mathrm{C}$ and virtually no logging can presently be done above $250^{\circ} \mathrm{C}$. Yet geothermal wells hotter than $300^{\circ} \mathrm{C}$ are not uncommon and development of magma resources will require equipment that operates above $500^{\circ} \mathrm{C}$. There is a need for improved, hightemperature equipment, especially to measure temperature, pressure, and flow rate downhole, in addition to the other physical parameters listed in the paragraph above.

- Log interpretation. Most geophysical well logs have been calibrated by the petroleum industry for use in the soft-rock oil and gas environuent. These logs have different responses in the hard-rock geothermal environment. For example, the so-called "neutron porosity log" measures porosity in the soft-rock environment by detecting the protons of water molecules in the pore spaces. In the hard-rock environment; however, water of crystallization, bound in several important igneous minerals, responds to this $l o g$ and a false, inflated reading of porosity results. Nearly every available log suffers from some such problem in the geothermal environment. The solution to these problems is at least two-fold. Better interpretation techniques for logs calibrated in the geothermal environment are needed as is the development of new logs especially designed for geothermal problems.

- Downhole sampler. A substantial amount of information could potentially be obtained from a sample of the native reservoir fluid, uncontaminated by drilling fluids and with its dissolved gases still present. A complete geochemical characterization of such a sample would develop data useful for chemical geothermometry, determination of water/rock and water/water interactions in reservoir development, and potential precipitation, scaling, and corrosion studies. There is no reliable downhole sampler available today for temperatures in excess of perhaps $200^{\circ} \mathrm{C}$.

In addition, adaptation of such quantitative chemical tools as specific ion electrodes and chemically-sensitive field effect transistors to the geothermal environment has the promise of yielding quantitative downhole chemical tools, but this adaptation has not yet been attempted to any significant degree. 


\subsubsection{Deliverability Testing -- Single Well}

Once a well has been drilled and completed, there is an attempt to determine if it is capable of production or is suitable for injection, as the case may be. A production test usually involves, at first, simply introducing a gas part way down the well, which then expands as it mores upward and decreases the weight of the fluid column (the so-called "gas lift"). This may stimulate the well to flow. If not, then a pump may be used to force flow. An injection test involves pumping fluid down the well. During all such tests, accurate measurement: of flow rate, temperature, and pressure are needed, preferably both downhole and at the surface. Production tests range in duration from a few hours to several months -- the longer-term tests are used for reservoir engineering purposes and are further discussed in Section 3.2.1.

- Improved techniques to measure quantity and quality of fluid during and just after drilling. During drilling, potentially productive horizons are sometimes flow tested using the so-called "drill stem test", in which fluids are pumped up the drill stem from a packed-off interval in the we1l. Just after drilling, liml.ted flow tests are conducted by gas lift or pumping. Improvements in packers, flow meters, pressure gauges, and thermometers are needed for such tests, as well as improved equipment for obtaining an uncontaminated sample of the fluid which still contains its dissolved gases (see next item).

- Improved geochemical characterization. Complete and uncontaminated fluid samples are rarely obtained during or just after drilling and much geochemical information is, therefore, 1ost. For example, determination of the long-term behavior of the reservoir is highly dependent on a knowledge of the undisturbed reservoir fluid chemical and physical properties, including dissolved species, $\mathrm{pH}$, $\mathrm{Eh}$, temperature, and pressure. Better methods are needed for early determination of these quantities in situ. 


\subsubsection{Completion Technology}

Well completion is the process of cleaning the drilling

fluids from the well and the adjacent formation, cementing production casing into place, hanging and possibly back-filling slotted production liner, and otherwise preparing the well for production or injection. Geothermal production well completion can also involve the emplacement of a downhole pump. Completion procedures for petroleum we1ls are not uniformly applicable in the geothermal environment.

- Improved materials and cement. Cements are required to bond the solid portions of the casing to the wallrock. They must be capable of withstanding oscillations of temperature and pressure as well as the corrosive effects of the geothermal environment. Complette bonding, with no bubbles between the casing and the wallrock, is required because the fluid in any such bubble can exprand as a result of temperature increase when the well is produced, leading to casing failure. Available cements and casing materials are not wholly satisfactory and improvements are needed.

- Improved perforation equipment. Wells must often be cased completely to prevent collapse and this, of course, cases off potential aquifers. Standard practice is to use geophysical well logs to locate potential zones of porosity in the formation and then to perforate the casing using some type of boring or explosive device at selected locations. There is a need to improve perforation equipment and techniques, especially for service above $200^{\circ} \mathrm{C}$.

- Improved methods of identifying fluid production and injection zones. Many of the remarks made under "High-Temperature, High-Pressure Borehole Instrumentation" (Section 3.2.3.3) apply here. Improvements in geophysical well logs are needed to help locate porous/permeable fluidfilled zones. One tool of high potential use in this application is the borehole televiewer, which cannot operate in wells whose temperature exceeds about $200^{\circ} \mathrm{C}$.

- More durable and reliable downhole pumps. There is no downhole pump that will operate at temperatures exceeding about $200^{\circ} \mathrm{C}$ and operational life of available pumps above $150^{\circ} \mathrm{C}$ is severely limited. This is in spite of DOE-sponsored research over the past several years. The biggest problem with electric submersible pumps is with fluid leakage into the electrical system due to failed motor seals. Limited success has recently been achieved by maintaining positive oil pressure inside all parts of the pump, but further development of this 
idea or other solutions are needed. The major problem with downhole line-shaft pumps is shaft bearing failure. There is also a practical emplacement depth limit for line-shaft pumps. Industry will need pumps to help maintain fluid pressure in the wellbore to prevent flashing of the geothermal fluid and to provide adequate fluid production rates for hydrothermal birary-cycle power plants. Pumps capable of use to over $300^{\circ} \mathrm{C}$ are needed.

\subsubsection{Scale Control}

During production of geothermal fluid and its subsequent use in surface power-plant equipment, chemical equilibrium is disturbed. In some cases, this disequilibrium can lead to precipitation of solid scale in the formation, drill casing, or surface equipment. In extreme cases, a wellbore can become completely choked off after only a few hours of production. Scaling can also take place in injection wells and associated equipment. Understanding and mitigation of these phenomena are required.

- Suppression. There are several techniques to prevent scaling in critical equipment. One is to prevent flashing, during which a major shift in chemical balance takes place in the wellbore, and allow it only under controlled conditions in specially-designed equipment. Another method is to add chemical components to the geothermal fluid that inhibit scaling. Improvements remain to be made in each of these techniques.

- Avoidance. In some situations, scaling can be prevented by such measures as maintaining the fluid under pressure by routing it through a heat exchanger and then directly to an injection wel1.

- Modeling of fluids in terms of precipitation and scaling. Numerical simulators, run on the computer, have the potential to model expected changes in fluid state in terms of potential precipitation of species from solution and scaling. Improvement to these modeling techniques and to the chemical thermodynamic data on which they are based are needed, as described under "Borehole Heat Transmission and Fluid Mechanics" (Section 3.2.3.7). Another line of investigation in need of research is the field of nucleation. The understanding of why some chemical species form a hard scale on pipes and equipment while others form solid particles or gels that remain suspended in the fluid and of how to control these processes is limited. 
- Reworking. Reworking of boreholes involves cleaning them out, cleaning the formation adjacent to the borehole, and restimulating flow. One of the common reworking techniques is simply to move a drill rig on site and drill the scale out of a well, but this is expensive. There are also chemical methods of reworking. Reworking promises to increase the productive lifetime of geothermal wells substantially, but more effective and less costly techniques are needed.

\subsubsection{Borehole Heat Transmission and Fluid Mechanics}

Several facets of geothermal development require a precise understanding of the flow of fluids and heat within a wellbore. Among these are: design of casings, cements, and casing installation procedures to withstand thermal shocks; design of casing interiors to minizize erosion, especially where the casing changes diameters; prediction of the enthalpy of the fluid available at the surface and existing downhole; and determination of the point where flashing, if any, of the thermal water to steam will take place in the wellbore. These problems are complex fluid mechanics problems that require further research work. Almost every geothermal developer today has a so-called "borehole simulator" to do these calculations, but none is very satisfactory.

- Multi-phase flow. In many producing geothermal wells, the water partly flashes to steam as it moves up the wellbore. This dramatically changes the flow characteristics of the fluid. Although the single-phase flow problem in a vertical pipe is well understood hydrodynamically and can be computer modeled, the multi-phase flow problem still needs additional work. Accurate computer simulation of multi-phase flow is needed in order to interpret results from well tests, to determine points of greatest casing erosion, to optimize flow conditions in the well, and to make the basic decision of whether or not to allow wellbore flashing during production.

- Thermodynamic properties of fluids. There is a wide-ranging need for determination of a number of the basic thermodynamic properties of geothernal. fluids. The equation-of-state of pure water is quite we11. known (i.e., the pressure of water 
and its vapor in equilibrium at a given temperature), but the corresponding equations-of-state for geothermal fluids that contain a few percent up to 30 percent dissolved salts and a number of dissolved gases are not known. The equation-ofstate is affected by the composition of the fluids, the ionic complexing, and the concentration of dissolved species. A great deal of basic measurement is needed here and industry is not likely to obtain and release such data.

- Chemical properties of fluids. Geothermal fluids are complex chemical systems. They undergo reactions with the reservoir rocks, with fluids fron other aquifers, with drilling fluids, with drill casing, and with surface equipment. In addition, changes in their pressure, temperature, or dissolved gases can cause chemical precipitation from them.

There are numerical. codes that are able to simulate the chemical changes expected of a fluid due to interaction with a solid or another fluid or due to changes in its state. These codes are time-consuming and costly to run, even on large computers. In addition, existing codes are not satisfactory because they are, in fact, quite simple simulations of extremely conplex chemical processes. Moreover, a great deal of the basic thermodynamic data needed to make these codes more realistic is not available.

Thus, there is a general need to upgrade the basic data base and current numerical codes. Such work would be profitable not only for the geothermal industry, but also for application by scientists working on nuclear waste isolation problems, in situ solution mining of mineral resources, development of petroleum reserves, and environmental protection from toxic wastes. Coordination among a number of separate research efforts currently being conducted in the federal sector on these problems is warranted.

\subsubsection{Environmenta1 Monitoring and Contro1}

Exhibit 6 identifies the prioritized research needs for environmental monitoring and control. The potential environmental problems associated with geothermal energy development have been recognized and studied for many years. Environmental problems are not currently proving to be a barrier to such development, although site-specific problems may be important considerations. Examples are: the odor nuisance of $\mathrm{H}_{2} \mathrm{~S}$ emissions at The Geysers geothermal 
FEDERAL RESEARCH NEEDS, PRIORITIES, AND LEVELS OF ACTIVITY: ENVIRONEENTAL MONITORING AND CONTROL

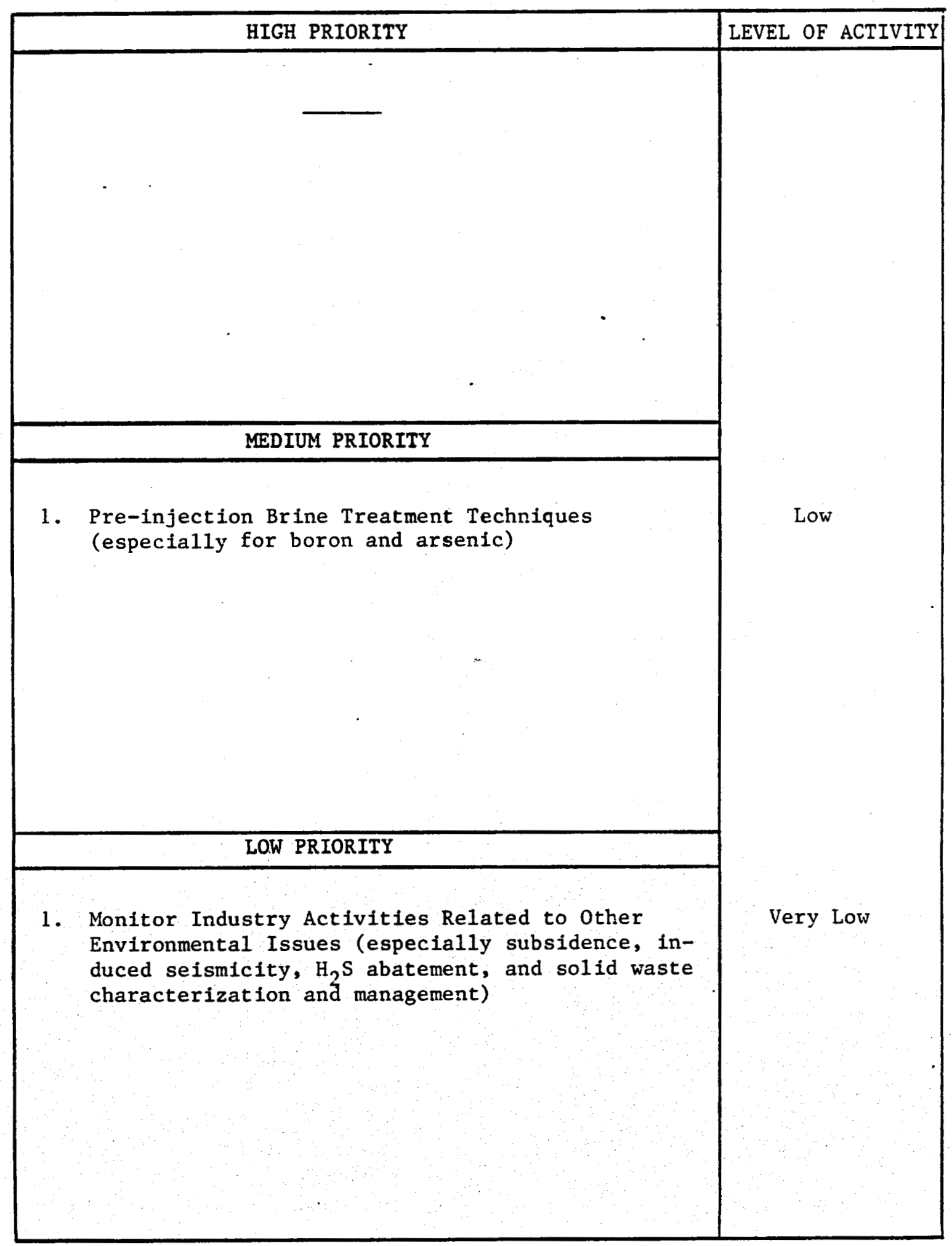


power complex, which has necessitated the design and installation of abatement systems; the potential for subsidence and resulting serious adverse effects at low-lyj.ng geopressured resource areas on the Texas-Louisiana Gulf Coast; and the very high salinity (up to 300,000 ppm of total-dissolved-solids) of hydrothermal resources in California's Imperial Valley, which poses certain fluid disposal questions.

No high-priority research needs have been identified. For the most part, site-specific activities and studies are the most appropriate manner to address environmental issues. However, some potential problems do exist and must be satisfactorily addressed. The only major federal role identified in this area concerns brine treatment to mitigate groundwater pollution. A minor federal role is appropriate for monitoring iadustry environmentalrelated activities.

\subsubsection{Pre-Injection Brine Treatment Techniques}

There is always a possibility of contaminating potable aquifers, which generally lie above thermal aquifers, any time geothermal fluids are produced or injected. However, state and federal regulations specify drilling, well completion, and production/injection measures that must be followed to monitor operations and prevent such contamination. That these measures are effective is attested to by the petroleum industry, which operates under these regulations with few if any failures.

However, some treatment techniques to remove especially harmful contaminants from the produced geothermal fluid before injection may be needed. In particular, boron and arsenic are of ten found in toxic 
quantities in geothermal waters. Cost-effective and reliable techniques for removing such :onstituents from chemica11y-complex geothermal fluids are not yet avażlable.

\subsubsection{Monitor Industry Activities Related to Other Environmental Issues}

Other potential environmental problems, for which industry is expected to take the lead role on an as-needed basis, are subsidence, induced seismicity, air emissions, and solid wastes.

- Subsidence. There is the possibility that if production of geothermal fluids lowers the pressure in the aquifer at depth, more of the weight of the overlying formations would be borne by the rock matrix of the aquifer, which might respond by compression. This process could ultimately lead to subsidence at the surface. Such subsidence has been observed, for example, in the Los Angeles basin as a result of petroleum production and in many areas of the west and elsewhere as a result of removal of more groundwater than is replenished. Subsidence has also been observed in some of the New Zealand hydrothermal fields. In the U.S., the Imperial Valley hydrothermal resources and the Gulf Coast geopressured resources probably have the greatest potential for subsidence of any of the areas likely to be developed over the next several decades. Imperial Valley resources sit in a sedimentary environment not unlike that found in the L.A. Basin. Geopressured resources have developed their overpressure (above hydrostatic pressure) by supporting part of the weight of the rock above.

One solution to subsicence will be provided in some areas by the requirement to inject spent fluids. Considerations of maintaining reservoir pressure and mitigating environmental pollution will dictate injection in any event. No specific research needs were identified in this area.

- Induced seismicity. Since fluids at depth can lubricate faults, movements of fluids into new environments can trigger stress release in the form of earthquakes. Such man-induced earthquakes were first widely noted in conjunction with the deep injection of waste waters at the Rocky Mountain Arsenal east of Denver, $C 0$. Since then, studies by the USGS have established a correlation between seismic activity and both production and injection at The Geysers, California. Earthquakes there have been shown to originate in production and injection zones and their magnitudes have been increasing over the last several years. Some of the larger events can be felt. 
The potential for inducing seismicity is a site-specific consideration in geothermal development. By regulation, the developer must monitor seismic activity in the vicinity of his development. It is believed that any induced seismicity would at least begin with events of low magnitude, far below the destructive range, and that these would be ample warning in the event a large event might be triggered.

No major research needs were identified for this topic.

- Air emissions. Geothermal fluids generally contain a few percent of gases. These gases usually are concentrated into the steam phase durtng flashing and consequently go into the plant rather than remaining with the fluids that are injected. Although the chief component of such gases is usually carbon dioxlde $\left(\mathrm{CO}_{2}\right)$, there is of ten also hydrogen sulfide $\left(\mathrm{H}_{2} \mathrm{~S}\right)$ in amounts too high to be environmentally acceptable. $\mathrm{H}_{2} \mathrm{~S}$ abatement systems have been under development, tested, and used at The Geysers for a number of years, but continued refinement of existing systems or development of new concepts is needed to bring down the costs of $\mathrm{H}_{2} \mathrm{~S}$ abatement.

- Solid wastes. Surface processing of geothermal fluids has the potential to cause production of solid material, usually silica or calcium-carbonate based. In highly-saline resources such as some of those in the Imperial Valley, there is potential for substantial quantities of such solids to be produced. Some of the constituents may cause an environmental contamination problem. There is, therefore, a need to physically and chemically characterize solid waste materials so that appropriate disposal procedures can be designed.

\subsection{Potential Research Performers}

A list of potential performers for the identified research needs was generated by the Pane1. The Panel in no way intended this list to be exhaustive, to identify preferred performers, or to recommend potential performers, nor was DOE/OER expecting any such Panel opinions. This list represents a sample of organizations with which the Panel members themselves are familiar and, furthermore, which are currently performing geoscience-related research.

Potential performers were identified for the three highest priority technology areas. The Panel did not feel familiar enough 
with the environmental area to identify relevant performers. The contractor, EER, Inc., offers instead a preliminary and partial list of organizations who have performed significant geothermal environmental research in the past; this list is not intended to reflect any preferences or: recommendations of EER, Inc. or the authors of this report.

\subsubsection{Reservoir Engineering}

- Nationa1 1aboratories

- Universities

- Stanford, Utah, Oregon, JC Riverside, Brown, Oklahoma, Pennsylvania State, UC Berkeley, San Dieto, Arizona, SMU, New Mexico, MIT, Texas

- Industry

- Terra Tek, S Cubed

- Federa1 government

- USGS

\subsubsection{Resource Exploration and Reservoir Definition}

- National laboratories

- Universities

- Federal government

- USGS

\subsubsection{Well Drilling, Completion, and Stimulation}

- National laboratories

- Sandia

- Universities

- Stanford, Louisiana (petroleum engineering), Oklahoma, Colorado School of Mines (petroleum engineering), Pennsy1vania State, UC Berkeley, Texas (petroleum engineering) 
- Industry

- Terra Tek, Baroid Group, Well Production Testing, Inc., Halliburton

- Federal government

- Bureau of Mines (scaling)

\subsubsection{Environmental Monitoring and Contro1}

- National laboratories

- Lawrence Livermure Laboratory, Lawrence Berkeley Laboratory, Pacific Northwest Laboratory, Los Alamos Scientific Laboratory, Oak Ridge National Laboratory, Idaho National Engineering Laboratory

- Universities

- Nevada

- Industry

- Air: Energy Technology Engineering Center (ETEC), EIC

Corp., Coury and Associates, Dow, SRI International, UOF, Inc.

- Liquids: Energy Resources Co., Inc.

- Solids: Acurex Corp.

- A11: WESTEC

- Federa1 Government

- DOE, EPA, USGS, DOI 


\subsection{SUMMARY OF RESEARCH NEEISS}

A wide variety of geoscience-related problems has been identified in this report. These problems stem from the technical and/or economic inadequacy of geoseience technology borrowed from the petroleum and minerals industries. In particular, there are many important fundamental differences between geothermal and petroleum resources which limit the effectiveness of technology adapted from the petroleum industry. The exploration and development of geothermal resources is much nore complex and demanding than petroleum applications due, for example, to the greater depths, harder rock, higher temperatures and pressures, fractured formations, and chemically-hostile fluids which sharacterize geothermal reservoirs.

Geothermal explorers and developers have been forced to utilize petroleum industry technology to locate, define, drill, mode1, and manage their resources because of the relatively recent emergence and the small size of the geothernal energy industry. This has created disincentives for major energy producers and for supply and service companies to develop new or modified technology for geothermal customers. By contrast, the petroleum and minerals industries possess a vast amount of empirical resource data (especially concerning long-term resource production) to draw on and an arsenal of proven techniques that have been continually refined over many decades at great expense to exploit globally-significant natural resources. The sma11 perceived market for geothermally-specialized technology does not encourage the diversion of private capital away from more economically attractive and/or less risky energy ventures. The inability to confidently predict the longevity and production 
behavior of geothermal resources continues to be a major barrier to increased private investment. It is for these reasons that the federal government has histcrically sponsored a substantial amount of geoscience-oriented $R \& D$ through a number of agencies.

Exhibit 7 summarizes the research needs appropriate for federal support in this context as identified by the Panel. The generic research needs are all high-priority and apply to all of the four technology areas; the generic needs are not presented in any order of priority. In the Exhibit, the "Reservoir Engineering" technology area is labelled " 1 " as the highest-priority area and the "Environmental Monitoring and Control" technology area is labelled "4" as the lowest-priority area. The research needs within each priority-group for each technology area are ranked on a 1,2,3... basis, indicating higher-to-lower importance.

It can be seen that all but two of the specific high-priority items are concerned with the interrelated tasks of developing field data collection and interpretation techniques tailored to geothermal applications, collecting the basic data needed to understand and predict the behavior of geothermal systems, and undertaking the data interpretation and modeling efforts indicated. Successes in these areas will be instrumental in overcoming the limitations of currently-used petroleum technology and in reducing the risks associated with geothermal energy investment. The remaining two high-priority research items ("Drilling Equipment and Techniques" and "Stimulation Techniques") are aimed directly at reducing field development costs; this will have a significant impact on the economics of geothermal energy projects since drilling accounts for 
FEDERAL RESEARCH NEEDS AND PRIORITIES

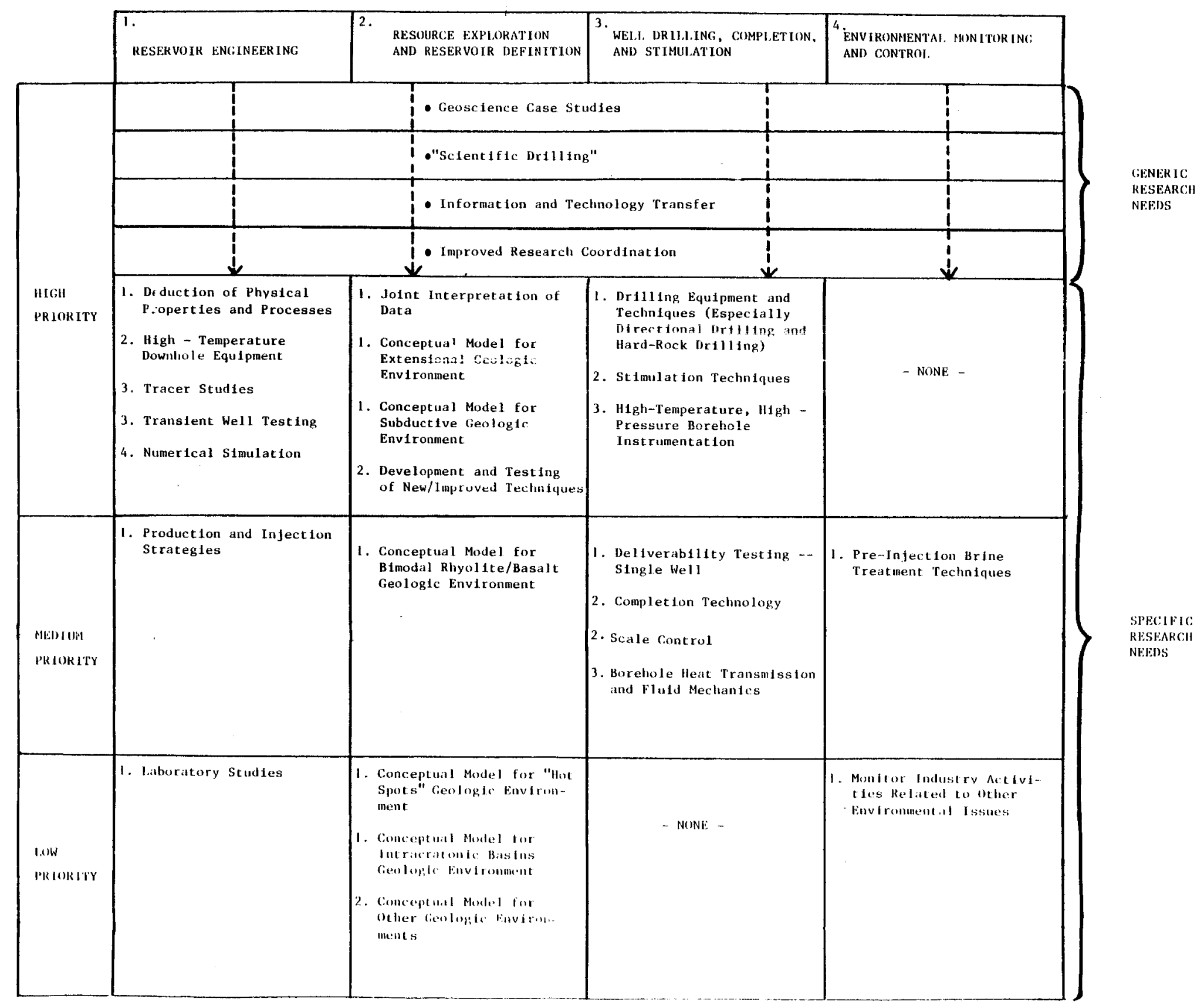


FEDERAL RESEARCH NEEDS AND PRIORITIES

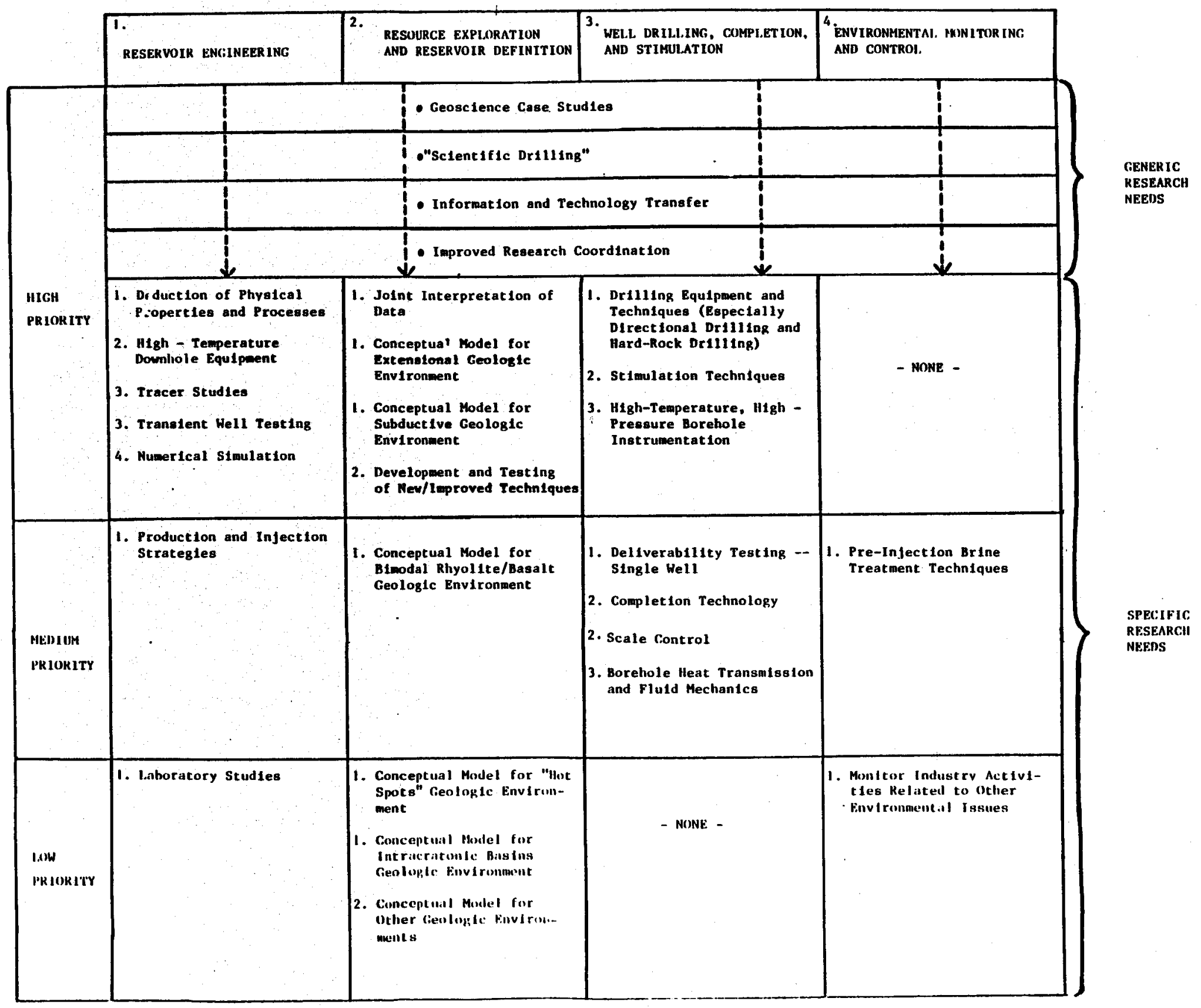


so much of the total resource development cost.

Both the group of med:ium-priority research needs and the group of low-priority needs comprise a mix of 1 tems which do not relate directly to a central objective to the extent that the group of high-priority needs does. Most of the medium- and low-priority items relate directly or indirectly to providing industry with the means to collect and analyze data on geothermal resources with a reliability and level of confidence approaching that characterizing the petroleum and minerals industries. However, a few items (especially the environmenta1 items) are essentially of a "support" nature and are concerned with the efficient operation of the energy conversion facility. 


\section{APPENDIX A}

INFORMATION SOURCES FOR R\&D PROJECTS 
The data collection effort for obtaining information on recently-completed and on-going geoscience-related R\&D projects involved both on-line and manual literature/information searching. On-1ine databases searched using Lockheed's DIALOG service were:

- SSIE Current Research (U.S. National Technical Information Service)

- DOE Energy (U.S. Department of Energy)

- GEOREF (American Geological Institute)

- GEOARChIVE (Geosystens, London, England).

Project information obtained from these on-line sources was supplemented by manual literature searches, using especially the following documents :

- The Geothermal Research Program of the U.S. Geological Survey, W. Duffield and M. Guffanti, Geologica1 Survey Circular 862.

- The Geothermal Research Program of the Geological Survey, W. Duffield and M. Guffanti, Open-File Report 81-564.

- Summary Outline of DOE Geoscience and Geoscience-Related Research, U.S. Department of Energy/Office of Basic Energy Sciences, Feb. 1982, NTIS No. DOE/ER-0120.

- Summaries of Physical Research in the Geosciences, U.S. Department of Energy/Office of Energy Research, Sept. 1982, NTIS No. DOE/ER-0145.

Contacts were made where possible with federal agencies to ensure that the project information was complete and accurate. 
APPENDIX B

THE ROLE OF GEOSCIENCES IN THE ASSESSMENT, EXPLORATION, AND DEVELOPMENT OF GEOTHERMAL ENERGY RESOURCES 
Geothermal energy is heat energy that originates within the earth. Two ultimate sources for the earth's internal heat appear to be most important among a nunber of contributing alternatives:

- Heat released throughout the earth's 4.5 billion-year history by radioactive decay of certain isotopes of uranium, thorium, potassium, and other elements

- Heat released during; formation of the earth by gravitational accretion and during subsequent mass redistribution when much of the heavier material sank to form the earth's core.

The relative contributions of these two mechanisms to the observed subsurface heat flow is not yet resolved. So active is the earth as a thermal engine, that many of the large-scale geological processes that have helped to form the earth's surface features are powered by redistributuion of internal heat as it flows from inner regions of higher temperature to outer regions of lower temperature. Such seemingly diverse phenomena as the motion of the earth's crustal plates, uplifting of mountain ranges, occurrence of earthquakes, eruption of volcanoes, and spouting of geysers all owe their origin to the transport of internal thermal energy. Under suitable circumstances, a small portion of this energy can be extracted and used by man.

In the United States and in many other countries, geothermal energy is used both for generation of electrical power and for direct applications such as space heating and industrial process energy. Although the technical viability of geothermal energy for such uses has been known for many years, the total amount of resource exploitation today is very small compared with the potential of the resource base. Availability of inexpensive energy from fossil fuels has been the major reason for the relatively slow pace of geothermal resource 
development. At present, geothermal applications are economic only at a few of the highest-grade resources. Development of new techniques and equipment to decrease costs of exploration, drilling, reservoir evaluation, and extraction of the energy is needed to make the vast1y more numerous lower-grade resources also economic.

A11 geothermal resources have three common components:

- A heat source

- Permeability in the rock

- A heat transfer f1aid.

Geothermal resource areas are generally those in which higher temperatures are found at shallower depths than is normal. This condition usually results from one of the following heat sources:

- Intrusion of molten rock to high levels in the earth's crust

- Higher-than-average flow of heat to the surface, with an attendant high rate of increase of temperature with depth (geothermal gradient), often found in broad areas where the earth's crust is thin

- Heating of groundwater that circulates to depths of 2 to 5 $\mathrm{km}$, with subsequent ascent of the thermal water near to the surface

- Anomalous heating of a shallow rock body by decay of an unusually high content of radioactive elements.

Permeability is a measure of how easily fluids flow through rock as a result of pressure differences. Fluid does not flow through the rock matrix itself, but rather through open spaces between mineral grains and through fractures. Rocks in many, but not all, geothermal areas are solid and tight, having little or no interconnected pore spaces between mineral grains. In such rocks, the only through-going pathways for fluid flow are cracks or fractures in the rock. A geothermal well must intersect one or more fractures or other permeable 
horizon if the well is to produce geothermal fluids in quantity. Fractures sufficient to nake a we11 a good producer need only be a few millimeters in width, but must be connected to the general fracture network in the rock in order to carry large fluid volumes. It is generally the case that fractures and other aquifers cannot be located precisely by means of surface exploration.

The function of the heat transfer fluid is to remove the heat from the rocks at depth and bring it to the surface. The heat transfer fluid is either water (sometimes saline) or steam. Water has a high heat capacity (anount of heat needed to raise the temperature by $1^{\circ} \mathrm{C}$ ) and a high heat of vaporization (amount of heat needed to convert $1 \mathrm{gm}$ to steam). Thus, water, which naturally pervades fractures and other open spaces in rocks, is an ideal heat transfer fluid because a given quantity of water or steam can carry a large amount of heat to the surface, where it can be easily removed.

Hydrothermal resources are those in which natural groundwater forms the heat transfer filuid. In hot dry rock (HDR) and magma geothermal systems, water or another fluid would have to be introduced to the hot horizons in order to transfer heat to the surface. Exhibit B-1 shows a simplified classification of geothermal systems. Geothermal resource temperatures range upward from the mean annual ambient temperature $\left(10-30^{\circ} \mathrm{C}\right)$ to we11 over $350^{\circ} \mathrm{C}$.

Geothermal development is an interdisciplinary endeavor. Geothermal occurrences are geological phenomena and, consequently, earth science information is needed for all phases of the development and for all major technical and financial decisions associated with a particular project. This critical involvement of the earth sciences 


\begin{tabular}{|c|c|}
\hline RESOURCE TYPE & $\begin{array}{c}\text { TEYPERATLRE } \\
\text { CHARACTERISTICS }\end{array}$ \\
\hline $\begin{array}{l}\text { Hydrothermal convection resources } \\
\text { (heat carried upward from depth } \\
\text { by convection of water or s-eam) } \\
\text { a) Vapor dominated } \\
\text { b) Hot-water dominated } \\
\text { i) High Temperature } \\
\text { ii) Intermediate Temperature } \\
\text { iii) Low Temperature }\end{array}$ & $\begin{array}{l}\approx 240^{\circ} \mathrm{C} \\
150^{\circ} \mathrm{C}-350^{\circ} \mathrm{C}+ \\
90^{\circ} \mathrm{C}-150^{\circ} \mathrm{C} \\
<90^{\circ} \mathrm{C}\end{array}$ \\
\hline $\begin{array}{l}\text { Hot rock resources } \\
\text { (rock intruded in molten fo:m } \\
\text { from depth) } \\
\text { a) Part still molten } \\
\text { b) Not molten } \\
\text { (hot dry rock) }\end{array}$ & $\begin{array}{l}>600^{\circ} \mathrm{C} \\
90^{\circ} \mathrm{C}-650^{\circ} \mathrm{C}\end{array}$ \\
\hline $\begin{array}{l}\text { Other resources } \\
\text { a) Sedimentary basins } \\
\text { (hot fluid in sedimentary' } \\
\text { rocks) } \\
\text { b) Geopressured } \\
\text { (hot fluid under high } \\
\text { pressure) } \\
\text { c) Radiogenic } \\
\text { (heat generated by } \\
\text { radioactive decay) }\end{array}$ & $\begin{array}{l}150^{\circ} \mathrm{C}-200^{\circ} \mathrm{C} \\
30^{\circ} \mathrm{C}-150^{\circ} \mathrm{C}\end{array}$ \\
\hline
\end{tabular}

ifter White, D.E., and Willimas, D.L., 1975, Assessment of Geothermal Resources of the United States-1975: U.S. Geo. Survey Circ. 726, 155p. 
is similar to that required for the development of petroleum and mineral reserves. However, the petroleum and minerals industries are well established, whereas tre geothermal industry is far less mature. The petroleum and minerals industries have developed earth science tools and techniques to solve their particular problems in an optimum way, which has required the expenditure of tens of billions of dollars. By contrast, relatively little has been spent in developing earth science tools and techniques especially to solve problems in the geothermal environment. The geothermal industry is not yet sufficiently profitable and organized to be able to fund the research and technology development necessary to meet these special needs. Geothermal developers have had to resort to the use of existing earth science tools, which have not generally been satisfactory. In some cases, no tools or techniques have existed to solve a particular problem.

Another problem stemming from the relationship of the geothermal energy industry to the petroleum industry is that geothermal energy development has historically represented insufficient demand for petroleum industry supply and service companies to meet its special needs except, perhaps, when petroleum industry activity is low and these companies are seeking new customers. Even when existing petroleum technology can be utilized for geothermal applications, there are times when petroleum industry requirements severely limit the availability of supplies and services (for example, during periods of high oil and gas drilling activity, it can be difficult to obtain drilling rigs for geothermal exploratory and production dril1ing). 
The geosciences have two primary applications in geothermal development:

1) Exploration for geothermal systems, and

2) Exploration within geothermal systems, with consequent development of a conceptual resource model.

Exhibit B-2 indicates one suggested series of steps for this exploration. The reconnaissance stage is designed to filter available prospect areas and to prioritize them for detalled exploration. These two stages refer to (1) above, i.e., exploration for geothermal systems. Once a geothermil system has been located, exploration becomes more detailed within the system. The primary objective of both phases of this exploration is to select drill sites--drill sites to locate a resource area, to confirm the presence of a resource, and then to obtain production of fluids for the utilization plant and to dispose of spent fluids through injection. Since the drilling of geothermal wells is so costly, refinement of exploration techniques has great potential for lowering development costs by avoiding wasted drill holes.

Once a geothermal system has been explored to a certain extent, the scientists and engineers working on the project can begin to form a conceptual resource model. Exhibit B-3 indicates this process. Data input to the model comes from the fields of geology, geochemistry, geophysics, and hydrology. These data are preferably detailed enough to be a function of the 3 space coordinates and of time $(x, y, z, t)$. The conceptual resource model is, in turn, used to make predictions for use in further exploration and in reservoir engineering and management. The conceptual model is continually refined by comparison of predictions to the known situation. 


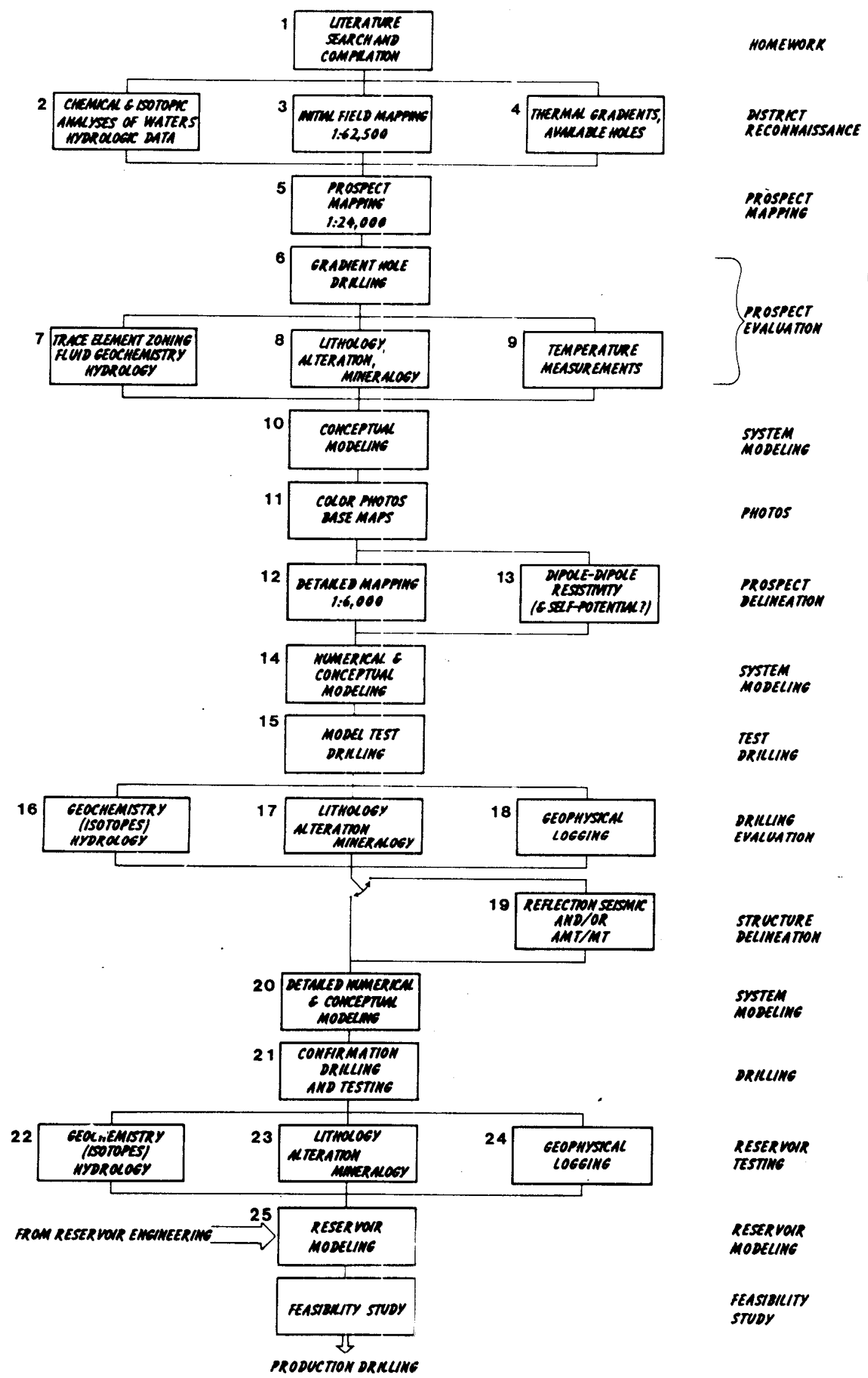

RECONNAISSANCE EXPLORATION

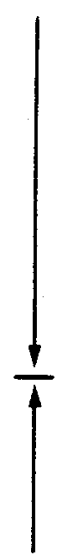

DETAILED EXPLORATION

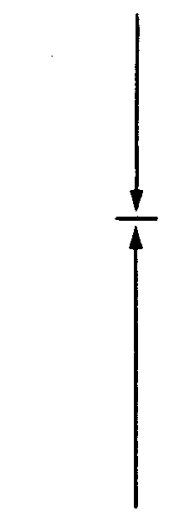

CONFIRMATION

DRILLiNG

TESTING

From: Ward, E.H., et.al., AAPG Bull. Vol. 65, p. 86-102, 1981 


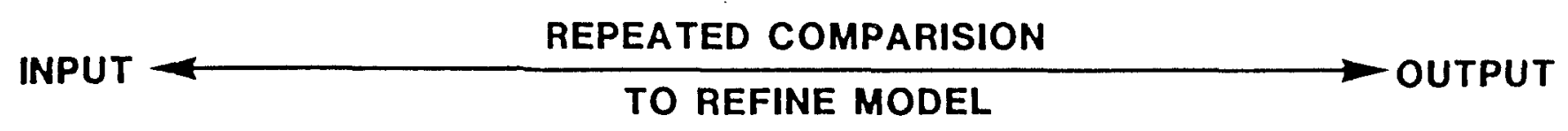

IOBSERVATIONS COLLECTED

ON SURFACE \& IN DRILL HOLES)
(PREDICTIONS BY GEOSCIENTISTS

\& ENGINEERS)

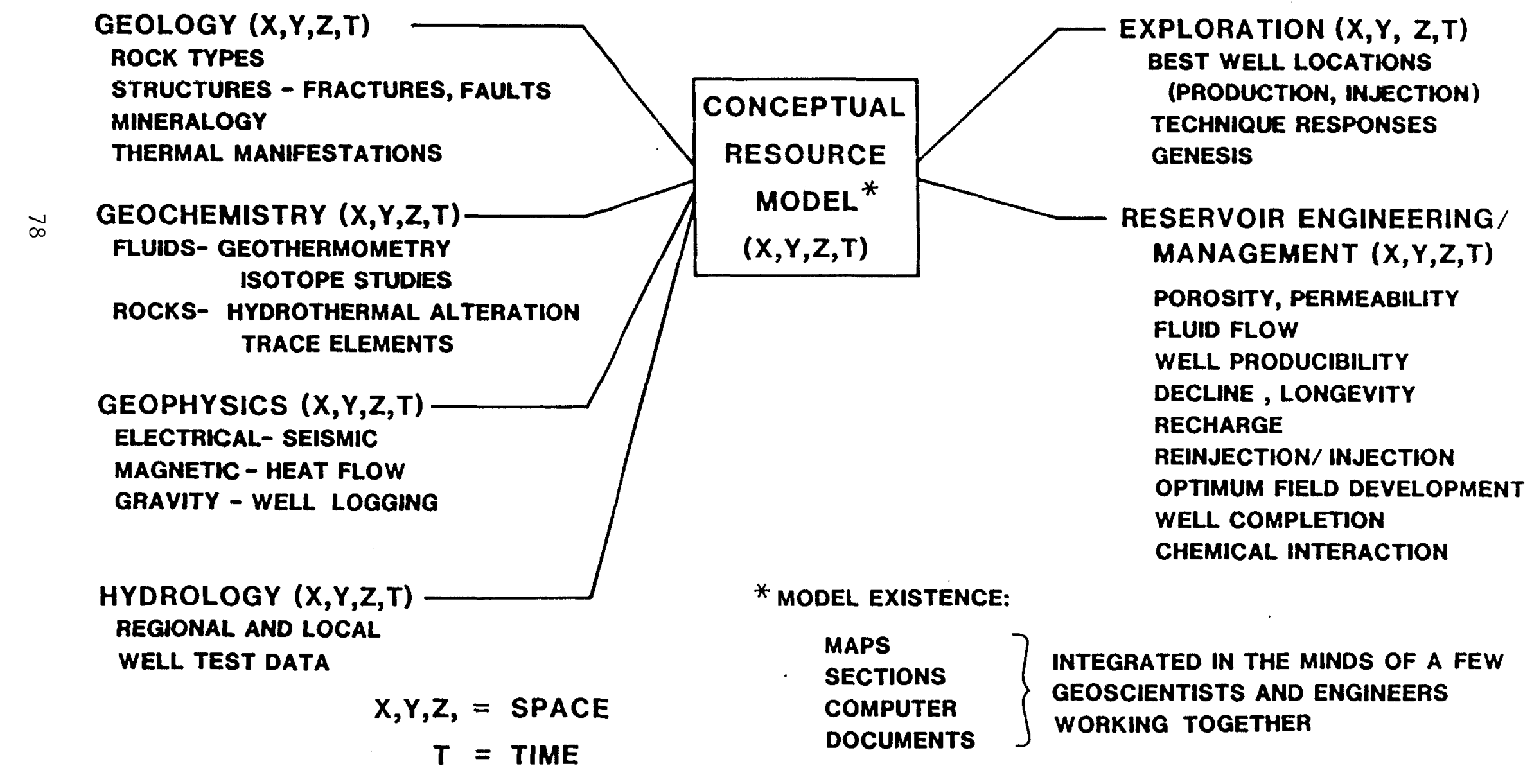


Even though the development and refinement of such a resource mode1 has gone on for more than 20 years at The Geysers, developers there are still unable to predict with certainty the boundaries of the resource, the best places to drill a well, and such important reservoir engineering parameters as optimum field development strategies or longevity. A great deal more research and development will be required to provide techniques for the industry to increase the reliability of such predictions. A similar situation exists in exploration for new geothermal resources. Statistics show that, outside of The Geysers and the Imperial Valley geothermal systems, only about 1 wildcat geothermal well in 10 is successful in the hightemperature hydrothermal environment*. Federal assistance in upgrading exploration, reservoir definition, and reservoir engineering techniques is clearly needed. These special geoscience-related problems faced by geotherinal. energy explorers and developers and the associated $R \& D$ needed to produce adequate technology in this area are discussed in the main body of this report.

*See the annual review of geothermal drilling activities published each year in Geothermal Energy magazine. 